\title{
Multi-product Firms and Product Quality Expansion
}

\author{
Van Pham $^{1}$ \\ The University of New South Wales \\ Alan Woodland ${ }^{2,3}$ \\ The University of New South Wales
}

28th February 2020

${ }^{1}$ School of Economics, University of New South Wales, e-mail: t.v.pham@unsw.edu.au.

${ }^{2}$ Corresponding author: School of Economics, University of New South Wales, e-mail: a.woodland@unsw.edu.au.

${ }^{3}$ Woodland gratefully acknowledges that this research was supported by a grant from the Australian Research Council (DP140101187). 


\begin{abstract}
This paper develops and analyzes a model of international trade comprising multiproduct firms that can produce a range of product varieties distinguished by quality. First, it analyses the within-firm distribution of product quality and argues that firms' export decisions are sensitive to their sizes and their product quality level. Specifically, a firm successfully exports both its high-end products and low-end products. Also, the sales of its top-end products relative to sales of its lower-end products is sensitive to the extent to which effective labour costs rise with quality. Second, the paper explores the heterogeneous effects of trade liberalization on multi-product firm behaviour and quality range choices. Under trade liberalization, small domestic firms experience a shrinkage of their product quality range, while even the new small-sized exporters narrow their product quality range to focus on an export variety. In contrast, existing exporters (large firms) can compete on both price and quality under trade liberalization by expanding their export product range toward both the low-end and high-end varieties. There is a greater expansion toward the lower-end varieties relative to the higher-end varieties under trade liberalization, this relative expansion decreasing as the variable trade cost decreases.
\end{abstract}

Keywords: Firm heterogeneity; Multiproduct firms; Quality range of varieties; Exports; Productivity JEL codes: F12; F13; L11; L23; L25 


\section{Introduction}

How do multi-product firms respond to trade liberalization? Should they be successful with their low-cost products or high-end products? Should they be successful with their low quality or high quality products? There have been inconsistent answers to these questions from the international trade literature. The horizontal product differentiation literature focuses on the price competition between firms, i.e., a firm can only export if its product is cheaper than its competitors' and, among its multiple products, only the cheapest products succeed (Mayer et al. (2014)). Meanwhile, studies on vertical product differentiation suggest that successful exporters sell higher quality products than its competitors (Kugler \& Verhoogen (2012), Hallak \& Sivadasan (2013)), and the top quality products are the best sellers for multi-product firms (Eckel et al. (2015), Manova \& Yu (2017)). It is, however, not rare to see firms that sell multiple products stretch their product range to both high-end and low-end varieties even within a narrowly defined product line.

Within this context, we develop a theoretical model of international trade in which heterogeneous firms produce varieties of products distinguished by their quality. We examine conditions under which firms produce only for the domestic market and conditions under which they also serve the foreign market. There are two fundamental contributions to the literature that emerge from this model and analysis.

First, this paper shows that multi-product firms compete on both product price and product quality, and a multi-product firm can extend its product range toward both ends of the quality ladder. With the focus on the distribution of product quality and export prices within firm, this paper contributes to a recently emerging body of literature that unifies two branches of literature on product differentiation and addresses the product quality choice and export pricing strategy, i.e., whether a firm exports its most expensive high-end products or its cheapest products ((Eckel et al. (2015); Manova \& Yu (2017); and Antoniades (2015)). It is found in this literature that for sectors where the goods are rather homogenous or firms have limited ability to differentiate the quality of their products, competition on prices would be more efficient, whereas, for more differentiated goods sectors exporters tend to succeed with quality competition and higher prices. Hence, firms' core products are expected to be the cheapest ones in the homogeneous goods sector, and the most expensive and higher quality ones in the differentiated good sector.

As a new contribution to this literature, our paper demonstrates a nonlinear relationship of the export productivity cutoff with respect to product quality. Particularly, the export productivity cutoff follows a V-shape curve with respect to quality, where high 
productivity is required for a firm to export either low quality or high quality products. Consequently, as a firm becomes more productive, it can export a larger product quality range of both lower-end varieties and higher-end varieties. Since a higher quality product is more costly to produce, in term of either a higher investment in $\mathrm{R} \& \mathrm{D}$ or more labour costs to create the high quality, only more productive firms can invest to improve the quality of their product. Low productive firms will, thus, produce low-end products; nevertheless, they still lose to the more productive firms, which can produce a same quality product at a lower cost, in the low-end market. The relative sales of the high-end varieties and low-end varieties within a firm depends on the effective labour cost elasticity with respect to quality in the production technology; specifically, the top-end varieties would exhibit relatively less sales if it is more costly to raise quality.

Second, our paper focuses on the effects of trade liberalization on the quality choice of multi-product firms. Particularly, we ask which of the two factors - competition on price or competition on quality - would play a larger role in determining the product range of a firm under trade liberalization, and whether those effects are homogenous across firms. The effect of trade liberalization has not been discussed in other studies on quality differentiation and multi-product firms, including Eckel et al. (2015) given their structure of single firms facing a frictionless world and Manova \& Yu (2017) given their focus on firms' hierarchy of products across markets. This focus puts our paper more in line with Bernard et al. (2011). However, in their paper there is no actual quality differentiation across within firm products, i.e., no difference in the production costs, and thus, no price differentiation across varieties of different attributes within a firm. Furthermore, they suggest that a reduction in trade cost only induces firms to extend their export product range toward the low attribute products without any improvement in the product quality/attribute of firms.

We show that, under a reduction in the variable trade cost, the productivity cutoff to produce a product of any quality level domestically will increase, while the productivity cutoff to export it will decrease. Accordingly, a firm will extend its export product range toward both ends of the quality ladder. The low-end is, nevertheless, found to be more responsive to trade cost than the high-end. In other words, trade liberalization promotes more competition on price than it does on competition on quality across firms; there will be more chance for low-end exporters, as well as more existing exporters, to extend their low-end export products. The relative responsiveness of a firm's low-end product range over its high-end range is determined by the trade costs, the cost elasticity for quality, and the efficiency of the R\&D investment in quality. Specifically, the relative responsiveness at the low-end will be small, i.e., the encroachment to the low end market 
would be limited relative to the expansion to the high end market, if the transport cost between the two countries is low, the fixed export cost is high or it is more costly to raise quality.

Related literature The current paper is related to several strands of the international trade literature. First, it is related to studies on price competition in multi-product firms. A major result arising from studies by Eckel \& Neary (2010) and Mayer et al. (2014) is that, among a firm's multiple products, the cheapest products succeed in the export market. In their models, firms export their core products and drop peripheral products with higher marginal costs. While we also establish that more productive firms have larger product ranges in both domestic and export markets and that a firm only exports its best performing products, the specification of these best performing products is different in our model. In Eckel \& Neary (2010) and Mayer et al. (2014) they are a firm's cheapest products, but in our model they are the highest quality and most expensive products.

Second, our paper is also closely related to the literature on product quality competition amongst single-product firms. This literature establishes that successful exporters sell higher quality products (and use higher quality inputs and labour) than their less successful competitors. Notable studies include Verhoogen (2008), Khandelwal (2010), Baldwin \& Harrigan (2011), Fajgelbaum et al. (2011), Crozet et al. (2012), Kugler \& Verhoogen (2012), Johnson (2012) and Hallak \& Sivadasan (2013). Our paper is most closely related to Antoniades (2015), who focuses on both quality competition and price competition. Our model, with multi-product firms and quality differentiation, suggests that the responses of firms to trade liberalization are heterogeneous and dependent on firms' productivity. The least productive firms can only compete by lowering their prices and quality, but more productive firms can compete on both product quality and price. Our extension to multi-product firms allows us to explain the variation in the scope of products and prices within firms, across firms in a market and across markets that single-product firm models are unable to do.

A third strand of literature to which our paper relates concerns multi-product firms and competition on both product price and product quality. Notable studies include Bernard et al. (2011), Eckel et al. (2015), and Manova \& Yu (2017). A major result arising from this literature is that a firm may choose to compete on price or compete on quality depending on the characteristics of its products. In more homogeneous goods sectors, competition on prices is more efficient and firms' best sellers are their cheapestlowest quality products. In more differentiated goods sectors, exporters succeed better 
with quality competition and the highest quality-highest priced products are the best sellers for multi-product firms. In contrast with this literature, we show the dynamics of firms' competition strategy in which firms can compete on both price and quality in the differentiated goods sector. Productivity and product quality (or prices) have a nonlinear relationship. More productive/larger size firms do not only export products of higher prices and higher quality but also export cheaper and lower quality products. This finding helps to reconcile the two branches of literature on vertical and horizontal product differentiation.

Fourth, our paper also relates to Bustos (2011) and Gervais (2015) as part of a large literature on trade and innovation. Our model is in line with Bustos (2011), which suggests that export profit can compensate the domestic loss and encourage firms to adopt the high technology to upgrade their products. Gervais (2015) also shows that the low end of the quality ladder is more responsive to variable trade costs than the high end, a result similar to one that we derive with a different model structure.

The rest of the paper is organized as follows. In section 2 we present the model of international trade in which multiproduct firms, with different productivities, produce a range of product varieties distinguished by quality, with different costs. We also establish productivity and quality cutoffs for firms to service domestic and foreign markets. Section 3 analyses the within-firm distribution of product quality and price choices of multiproduct firms, and how these choices relate to productivity and to exporting. Section 4 is devoted to consideration of the implications of trade liberalization upon the export decisions of firms and, more importantly, to the effects upon the quality ranges of products produced by multiproduct firms in both the domestic and export markets. Section 5 provides a numerical illustration of the major theoretical predictions. Finally, section 6 concludes the paper.

\section{The model}

The model considers two symmetric countries. In each country, there is a continuum of firms indexed by $i$ and each firm produces a continuum of quality-differentiated varieties indexed by its perceived quality $\lambda$. Firms are differentiated by their labour productivities $\varphi_{i}$, which are assumed to be randomly drawn from a nation-wide productivity distribution $g(\varphi)$. The household sector comprises a representative consumer, who has preferences over consumptions of goods distinguished by brand $(i)$ and quality $(\lambda)$. Trade is allowed between the two countries with a "melting-iceberg" transport cost. The model assumes away foreign direct investment, so that the only access to a foreign market is 
via exporting.

\subsection{Final consumer}

Consumers face a continuum of varieties differentiated by their quality and brand. The representative consumer has preferences described by a constant elasticity of substitution (CES) function

$$
U=\left[\int_{\lambda \in \Lambda}(\lambda Q(\lambda))^{\frac{\theta-1}{\theta}} d \lambda\right]^{\frac{\theta}{\theta-1}}
$$

where $Q(\lambda)$ is a consumption index, which also takes a CES form given by

$$
Q(\lambda)=\left[\int_{i \in I^{d}} q_{i}^{d}(\lambda)^{\frac{\sigma-1}{\sigma}} d i+\int_{i \in I^{x}} q_{i}^{x}(\lambda)^{\frac{\sigma-1}{\sigma}} d i\right]^{\frac{\sigma}{\sigma-1}} ; \quad \lambda \in \Lambda .
$$

In these expressions, $\Lambda=[1, \bar{\lambda}]$ is a set of available quality levels bounded by the

world technology frontier $\bar{\lambda}, I=I^{d} \cup I^{x}$ is the set of brands (firms), $q_{i}^{d}(\lambda)$ and $q_{i}^{x}(\lambda)$ are the consumptions of each domestic variety and imported variety of quality $\lambda, \theta>1$ is the elasticity of substitution between quality-differentiated varieties from a same brand, and $\sigma>1$ is the elasticity of substitution between brand-differentiated varieties of the same quality. In order to simplify the derivation further below, while maintaining the dual heterogeneity (in terms of quality and ability) in the supply side, which is the major focus of this model, the two elasticities of substitution, $\theta$ and $\sigma$, are assumed to be equal.

To maximize her utility subject to the budget constraint

$$
\int_{\lambda \in \Lambda} \int_{i \in I} p_{i}(\lambda) q_{i}(\lambda) d i d \lambda=Y
$$

the consumer's demand for each domestic variety is

$$
q_{i}^{d}(\lambda)=Y P^{\theta-1} p_{i}^{d}(\lambda)^{-\theta} \lambda^{\theta-1}
$$

and, similarly, for each imported variety is

$$
q_{i}^{x}(\lambda)=Y P^{\theta-1} p_{i}^{x}(\lambda)^{-\theta} \lambda^{\theta-1}
$$

where $Y$ is the given national expenditure, $p_{i}^{d}(\lambda)$ and $p_{i}^{x}(\lambda)$ are the domestic and imported prices of each variety, and $P$ is the (quality-adjusted) aggregate price index of all 
the final good varieties

$$
P=\left\{\int_{\lambda \in \Lambda}\left[\int_{i \in I^{d}}\left(\frac{p_{i}^{d}(\lambda)}{\lambda}\right)^{1-\theta} d i+\int_{i \in I^{x}}\left(\frac{p_{i}^{x}(\lambda)}{\lambda}\right)^{1-\theta} d i\right] d \lambda\right\}^{\frac{1}{1-\theta}}
$$

In this preference specification, higher quality varieties yield higher utility. Accordingly, the demand functions (4) and (5) depend positively on the level of quality of the variety, $\lambda$.

\subsection{Technology}

To produce a variety of its product, a firm $i$ with productivity $\varphi_{i} \geq 1$ employs labour. The amount of labour needed to produce one unit of output with base quality $\lambda=1$ is $1 / \varphi_{i}$, while the amount of (effective) labour needed to produce one unit of output of quality $\lambda$ is $\lambda^{\beta} / \varphi_{i}$ where parameter $\beta \in(0,1)$. Thus, the effective labour requirement is increasing in quality at a decreasing rate. The production function for a firm with productivity $\varphi$ therefore has the form

$$
q(\lambda, \varphi)=\varphi \frac{L}{\lambda^{\beta}}
$$

where $L$ is the employed labour of the firm.

In this model, labour is unskilled and homogenous, and the size of the local labour market is assumed to be sufficiently large that labour can be hired from the local market at a constant wage rate, which is normalized to 1 . In this case, the marginal cost of producing one unit of a $\lambda$ quality variety by a firm with productivity $\varphi$ is

$$
c(\lambda, \varphi)=\frac{\lambda^{\beta}}{\varphi}
$$

The parameter $\beta$ may be interpreted as the elasticity of marginal cost with respect to quality since $\frac{\partial \ln c(\lambda, \varphi)}{\partial \ln \lambda}=\beta$.

In order to produce a variety of quality $\lambda$, each producer also needs to make a fixed investment (of effective labour) of

$$
f(\lambda)=\lambda^{r}
$$

to have a production capacity compatible with the targeted quality of the product, where $r>0$. This quality investment can be understood as a R\&D investment in the quality of the product, or a purchase of a compatible production line, or an advertising expenditure 
to raise the perceived quality of the firm's output. As common in the product quality literature (e.g., Kugler \& Verhoogen (2012)), $\frac{1}{r}$ is the scope for quality differentiation, which characterizes the effectiveness of the R\&D or the advertising spending. The quality investment is increasing in the targeted product quality $\lambda$; it does not affect the productivity of the firm, nor is it affected by the productivity of the firm.

\subsection{Profit maximization}

The product quality range for each firm is endogenous and depends on its productivity and production technology. At each quality level, there is an endogenous mass of firms producing horizontally differentiated varieties of the same quality, and hence, monopolistic competition takes place in the market. The firm chooses the range of qualities to produce and the outputs of each quality variety to maximize profits. It has several market opportunities - to sell only in the domestic market, to only export or to sell in both the domestic and export markets.

Domestic profit function A firm operating only in the domestic market (the foreign market will be considered further below) chooses its price and output to maximize domestic profit given by

$$
p^{d}(\lambda, \varphi) q^{d}(\lambda, \varphi)-c(\lambda, \varphi) q^{d}(\lambda, \varphi)-f(\lambda)
$$

where $q^{d}(\lambda, \varphi)$ is determined by the demand function (4) and marginal cost $c(\lambda, \varphi)$ is specified in (8). As a result, it will set the price

$$
p^{d}(\lambda, \varphi)=\frac{1}{\rho} c(\lambda, \varphi)=\frac{1}{\rho} \frac{\lambda^{\beta}}{\varphi},
$$

where $\rho=\frac{\theta-1}{\theta}<1$, and produce output

$$
q^{d}(\lambda, \varphi)=Y P^{\theta-1}\left(\frac{1}{\rho} \frac{\lambda^{\beta}}{\varphi}\right)^{-\theta} \lambda^{\theta-1}=\rho^{\theta} Y P^{\theta-1} \varphi^{\theta} \lambda^{\theta(1-\beta)-1}
$$

The domestic profit function is

$$
\pi^{d}(\lambda, \varphi)=\theta^{-1} Y(\rho P)^{\theta-1} \lambda^{(1-\beta)(\theta-1)} \varphi^{\theta-1}-\lambda^{r} .
$$


Defining the constants $\kappa \equiv \theta^{-1} Y(\rho P)^{\theta-1}>0$ and $\gamma \equiv(1-\beta)(\theta-1)>0$, domestic profit may be expressed more compactly as

$$
\pi^{d}(\lambda, \varphi)=\kappa \varphi^{\theta-1} \lambda^{\gamma}-\lambda^{r}
$$

A firm will produce domestically if it makes a non-negative profit, and so its profit function is

$$
\pi(\lambda, \varphi)=\max \left\{0, \pi^{d}(\lambda, \varphi)\right\}
$$

Export profit function Consideration now turns to a firm's export decision. It is assumed that a final good producer is required to invest a fixed cost $f_{x}>0$ to enter the foreign market. ${ }^{1}$ This fixed cost comprises the firm's spending on marketing activities to make its product recognizable to the customers and its distribution setup costs in the new market. In addition, the firm is faced with a "melting-iceberg" transport cost factor of $\tau$ per unit, $\tau \geq 1$, i.e., $\tau$ units have to be shipped for one unit to arrive at the foreign country. Because of these additional costs of exporting, export profit will be lower than domestic profit and so a firm would never export a variety without also selling it in the domestic market.

The export price for each variety is chosen to maximize profits from exporting by setting marginal revenue equal to marginal cost, which now becomes $\tau c(\lambda, \varphi)$. Accordingly, the export price now reflects the domestic price and the iceberg transportation cost as in

$$
p^{x}(\lambda, \varphi)=\frac{\tau \lambda^{\beta}}{\rho \varphi}=\tau p^{d}(\lambda, \varphi)
$$

so its export demand, given by (5), can be written as

$$
q^{x}(\lambda, \varphi)=\tau^{-\theta} Y P^{\theta-1} p^{d}(\lambda, \varphi)^{-\theta} \lambda^{\theta-1}=\tau^{-\theta} q^{d}(\lambda, \varphi)
$$

If the firm sells in both the domestic and export markets, its profit function is given by

$$
\pi^{d+x}(\lambda, \varphi)=\left(1+\tau^{1-\theta}\right) \kappa \varphi^{\theta-1} \lambda^{\gamma}-\lambda^{r}-f_{x}
$$

It will, hence, export a variety if its combined profit from both the domestic market and

\footnotetext{
${ }^{1}$ Note that the R\&D investment $f(\lambda)$ incurs only once if a firm both produces this quality variety domestically and exports it.
} 
export market is non-negative and greater than its domestic profit. Its profit function is therefore redefined as

$$
\pi(\lambda, \varphi)=\max \left\{0, \pi^{d}(\lambda, \varphi), \pi^{d+x}(\lambda, \varphi)\right\}
$$

The firm will produce domestically if and only if $\pi^{d}(\lambda, \varphi) \geq 0$, as noted further above. It will produce domestically and for the export market if and only if

$$
\pi^{d+x}(\lambda, \varphi) \geqslant 0 \text { and } \pi^{d+x}(\lambda, \varphi) \geqslant \pi^{d}(\lambda, \varphi)
$$

The firm is thus making two extensive margin decisions - whether to produce domestically and, conditional on doing so, whether to sell in the export market.

\subsection{Extensive margin decisions}

Given the nature of the profit function (18), there are several extensive margins to be considered. In the following, we consider four such margins and relate them to production and export choices of the firm.

Domestic production decision productivity cutoff We first consider a firm that only has the option of producing and selling domestically. A firm will produce domestically if it makes a non-negative profit, that is, if its productivity is no less than the zero-profit cutoff

$$
\varphi^{d}(\lambda)=\lambda^{\frac{r-\gamma}{\theta-1}} \kappa^{\frac{1}{1-\theta}}
$$

To exclude the unintuitive case that the domestic productivity cutoff is decreasing in quality, i.e., less productive firms can produce higher quality products and each firm can produce unlimited quality regardless of its productivity, it is assumed that

$$
r \geqslant \gamma=(1-\beta)(\theta-1)
$$

Intuitively, a firm needs to pay a sufficient large R\&D investment ( $r$ is sufficiently large) to produce a high quality product. The function $\varphi^{d}(\lambda)$ is increasing in $\lambda$ for all $\lambda \in \Lambda$ if $r>\gamma$ (condition (21) holds with strict inequality), as formally stated as Lemma 3 and proved in the Appendix.

The zero-profit condition in (20) can be inverted to obtain the zero-profit value of $\lambda$ 
as a function of productivity as in

$$
\lambda^{d}(\varphi)=\left[\kappa \varphi^{\theta-1}\right]^{\frac{1}{r-\gamma}}
$$

Using this expression, the domestic profit function in (13) can be rewritten as

$$
\pi^{d}(\lambda, \varphi)=\lambda^{\gamma}\left[\lambda^{d}(\varphi)^{r-\gamma}-\lambda^{r-\gamma}\right]
$$

An examination of this expression (23) for domestic profit reveals that the parametric restriction (21) implies that

$$
\begin{aligned}
& \pi^{d}(\lambda, \varphi)<0 \quad \text { for } \lambda>\lambda^{d}(\varphi) \\
& \pi^{d}(\lambda, \varphi) \geqslant 0 \quad \text { for } 1 \leqslant \lambda \leqslant \lambda^{d}(\varphi) .
\end{aligned}
$$

A firm with productivity $\varphi$ will produce any variety that yields non-negative profit to maximize its total profit, and hence $\left(1, \lambda^{d}(\varphi)\right]$ is the domestic quality range of a firm with $\lambda^{d}(\varphi)$ being the highest quality that the firm will produce and sell domestically. The expression $\lambda^{d}(\varphi)$ in (22) provides a formula for the zero-profit locus in $(\lambda, \varphi)$ space. Firms with higher productivity can produce higher quality varieties; conversely, the production of higher quality varieties requires the firm to have a higher productivity.

Export decision productivity cutoffs It is noted further above in (18) that the firm will export if and only if its profit from doing so is non-negative and is at least as great as the profit from the domestic market. We consider each of these requirements in turn.

First, by setting $\pi^{d}(\varphi, \lambda)=\pi^{d+x}(\varphi, \lambda)$, we obtain the productivity cutoff for the profit from selling only in the domestic market to equal the profit from also selling in the foreign market as

$$
\varphi^{L}(\lambda)=\tau\left(\frac{f_{x}}{\kappa}\right)^{\frac{1}{\theta-1}} \lambda^{\beta-1}
$$

Lemma 4 in the Appendix demonstrates that $\varphi^{L}(\lambda)$, indicating the productivity level that equates domestic and export profits, is a decreasing and convex function of variety quality.

Second, by setting $\pi^{d+x}(\varphi, \lambda)=0$, we obtain the productivity cutoff to produce and export a high quality variety as

$$
\varphi^{H}(\lambda)=\left(\frac{\lambda^{r}+f_{x}}{\kappa\left[1+\tau^{1-\theta}\right]}\right)^{\frac{1}{\theta-1}} \lambda^{\beta-1} .
$$


It is straightforward to demonstrate (see Lemmas 5 and 6 in the Appendix) that the function $\varphi^{H}(\lambda)$ has a unique minimum at $\lambda=\lambda_{M}$, where

$$
\lambda_{M}=\left[\frac{\gamma f_{x}}{r-\gamma}\right]^{\frac{1}{r}},
$$

and hence that it is a pseudoconvex function, which is decreasing for all $\lambda<\lambda_{M}$ and increasing for all $\lambda>\lambda_{M}$.

Third, we consider a productivity cutoff that equates both domestic and export profit function to zero. To that end, it will be convenient to define $\lambda_{H}$ as a quality benchmark at which the two profit curves intersect at the same point, as in

$$
\pi^{d}(\lambda, \varphi)=\pi^{d+x}(\lambda, \varphi)=0 .
$$

The solution for $(\lambda, \varphi)$ to these two equations is given by

$$
\begin{aligned}
& \lambda_{H}=\left(\tau^{\theta-1} f_{x}\right)^{\frac{1}{r}} \\
& \varphi_{H}=\varphi^{d}\left(\lambda_{H}\right)=\tau^{\frac{r-\gamma}{r}} f_{x}^{\frac{r-\gamma}{r(\theta-1)}} \kappa^{\frac{1}{1-\theta}} .
\end{aligned}
$$

Fourth, we can use these cutoff functions to obtain the productivity cutoff function for the decision of the firm to export. As noted above, and is implicit in the firm's profit function (18) and export decision rule (19), the firm will produce domestically and export if, and only if, it makes a positive profit and this profit exceeds the profit obtained by only servicing the domestic market. Thus, the export productivity cutoff function is

$$
\varphi^{X}(\lambda)=\max \left\{\varphi^{L}(\lambda), \varphi^{H}(\lambda)\right\} .
$$

The production productivity cutoff identifies when domestic firms will produce, either to sell domestically only or to sell domestically and export. The production productivity cutoff may be specified as

$$
\varphi^{D}(\lambda)=\min \left\{\varphi^{d}(\lambda), \varphi^{H}(\lambda)\right\} .
$$

Thus, the domestic firm will produce if its productivity level is sufficiently large to produce for the domestic market only or to produce for the export and domestic markets.

Properties of export and production decision productivity cutoffs To facilitate the analyses further below, it will be useful to first derive the salient properties of the 
profit cutoff functions defined in this section. Their properties are stated in the following lemmas, the proofs of which are relegated to the Appendix.

Lemma 1 The productivity cutoffs satisfy the following inequalities:

$$
\begin{array}{lll}
\varphi^{L}(\lambda)>\varphi^{H}(\lambda)>\varphi^{d}(\lambda) & \text { for } & \lambda<\lambda_{H} \\
\varphi^{d}(\lambda)>\varphi^{H}(\lambda)>\varphi^{L}(\lambda) & \text { for } & \lambda>\lambda_{H} .
\end{array}
$$

These inequalities lead to the following result, which provides an explicit representation for the production and export productivity cutoff functions defined by (32) and (31).

Lemma 2 The production and export productivity cutoff functions defined by (32) and (31) are given by

$$
\varphi^{X}(\lambda)= \begin{cases}\varphi^{L}(\lambda) & \text { for } \lambda<\lambda_{H} \\ \varphi^{H}(\lambda) & \text { for } \lambda>\lambda_{H}\end{cases}
$$

and

$$
\varphi^{D}(\lambda)=\left\{\begin{array}{lll}
\varphi^{d}(\lambda) & \text { for } & \lambda<\lambda_{H} \\
\varphi^{H}(\lambda) & \text { for } & \lambda>\lambda_{H}
\end{array}\right.
$$

Lemmas 1 and 2 formalize the point that a firm's export decisions depend on the quality of its product. The productivity cut-off to export a low quality variety is higher than the productivity cut-off to produce it domestically. Meanwhile, for high quality varieties the export productivity cut-off is the same as the domestic productivity cutoff because firms will always export high quality varieties if they can produce them domestically.

For a low quality variety, defined by $\lambda<\lambda_{H}$, the combined profit from exporting and selling domestically exceeds the domestic profit at the productivity cutoff $\varphi^{L}(\lambda)$ that is greater than the domestic productivity cutoff $\varphi^{d}(\lambda)$. If $\varphi \geqslant \varphi^{L}(\lambda)$, the firm will engage in exporting variety $\lambda$. However, if $\varphi^{d}(\lambda)<\varphi<\varphi^{L}(\lambda)$, the firm will only produce for the domestic market and not export this variety.

For a high quality variety $\lambda \geqslant \lambda_{H}$, the profit from selling in both the domestic and export markets is always greater than the profit from the domestic market only. In this case, the zero-profit domestic productivity cutoff $\varphi^{d}(\lambda)$ is higher than the export productivity cutoff $\varphi^{H}(\lambda)$ and, thus, if a firm produces a variety $\lambda$ it will always export that variety. This is a case where the production of a high quality variety for the 
domestic market only is very costly, and exporting can generate extra revenue for a firm to compensate for its loss in the domestic market.

In summary, a firm's export decision depends on the quality of its product. Specifically, all firms that can produce a high quality variety will always export this variety. However, not all firms that produce a low quality variety can export that variety - a firm can export a low quality variety if only it is more productive than other firms producing at the same quality level.

\subsection{Market aggregation}

To complete the model specification, it is necessary to determine the aggregate price index, $P$, which is endogenous. The price index, specified in (6) is an integral of the quality adjusted prices across all firms producing the same quality, and across all quality levels. Note that to have a definite solution to $P$, the set of quality levels $\Lambda$ is assumed to be finite in the sense that there is a finite upper bound $\bar{\lambda}$ of the integral over $\lambda$. This upper quality bound is determined by a given national technology frontier.

Following the previous analysis, the mass of firms selling in the domestic market must satisfy the production productivity cutoff $\varphi^{D}(\lambda)$, while the mass of firms that export must satisfy the export productivity cutoff $\varphi^{X}(\lambda)$. In addition, we note that a firm is identified by its productivity and so the distribution of firms is the distribution of productivity denoted by the density function $g(\varphi)$, whence $d i=g(\varphi) d \varphi$.

Using these observations, we can then rewrite the price index in (6) generally as

$$
P=\left\{\int_{1}^{\bar{\lambda}}\left[\int_{\varphi^{D}(\lambda)}^{\infty}\left(\frac{p^{d}(\lambda, \varphi)}{\lambda}\right)^{1-\theta} g(\varphi) d \varphi+\int_{\varphi^{X}(\lambda)}^{\infty}\left(\frac{p^{x}(\lambda, \varphi)}{\lambda}\right)^{1-\theta} g(\varphi) d \varphi\right] d \lambda\right\}^{\frac{1}{1-\theta}}
$$

and, using our solutions for domestic and foreign prices given by (10) and (15), more specifically as

$$
P=\frac{1}{\rho}\left[\int_{1}^{\bar{\lambda}} \lambda^{\gamma}\left[\int_{\varphi^{D}(\lambda)}^{\infty} \varphi^{\theta-1} g(\varphi) d \varphi+\tau^{1-\theta} \int_{\varphi^{X}(\lambda)}^{\infty} \varphi^{\theta-1} g(\varphi) d \varphi\right] d \lambda\right]^{\frac{1}{1-\theta}}
$$

To enable explicit expressions, it is assumed that productivity follows a Pareto distribution with the probability density function

$$
g(\varphi)=\left\{\begin{array}{cc}
k \varphi_{m}^{k} \varphi^{-(k+1)} & \varphi \geqslant \varphi_{m} \\
0 & \text { otherwise }
\end{array}\right.
$$


In this Pareto specification, the shape parameter $k>0$ describes the dispersion of the productivity distribution and $\varphi_{m}$ is the minimum value of $\varphi$. To have definite solutions for the integrals in the expression for $P$, it is assumed that $k>\theta-1$, a common assumption in the heterogeneous firm literature. Under this condition, the integral $\int_{a}^{\infty} \varphi^{\theta-1} g(\varphi) d \varphi$ appearing twice in (6) can be evaluated as

$$
G(a) \equiv \int_{a}^{\infty} \varphi^{\theta-1} g(\varphi) d \varphi=k \varphi_{m}^{k} \int_{a}^{\infty} \varphi^{\theta-1-(k+1)} d \varphi=\frac{k \varphi_{m}^{k}}{k-\theta+1} a^{\theta-1-k} .
$$

By substituting the two productivity cutoffs for $a$ in this integrand, the solution for the aggregate price index becomes

$$
P=\frac{Z(\tau)^{\frac{1}{1-\theta}}}{\rho}
$$

where

$$
Z(\tau)=\int_{1}^{\bar{\lambda}} \lambda^{\gamma}\left[G\left(\varphi^{D}(\lambda)\right)+\tau^{1-\theta} G\left(\varphi^{X}(\lambda)\right)\right] d \lambda .
$$

The price index (38) is endogenously determined by integrating the price of domestic and export varieties (qualities) over firms (productivity), taking into account the ranges of productivities and varieties produced and sold. The price index can be evaluated as the sum of two integrals, the integrands depending on the function $G(a)$ defined in (37) and the profit cutoff functions $\varphi^{D}(\lambda)$ and $\varphi^{X}(\lambda)$ as presented in (32) and (31). This price index depends on the iceberg transport cost factor, $\tau$, as well as on the parameters of the technology and preferences, of course.

\section{The export product quality range}

Attention now turns to establishing the equilibrium export product quality range and the domestic product quality range. Lemmas 1 and 2 formalize our discussion in subsection 2.4 that a firm's export decisions depend on the quality of its product.

With these lemmas in hand, we can depict the domestic and export quality ranges for firms of varying productivities in Figures 1 and Figure 2. We can also obtain the following propositions about these quality ranges. Here we list them, and then discuss them with the aid of the two figures.

Proposition 1 For low quality varieties such that $\lambda<\lambda_{H}$, (a) the minimum productivity cutoff to produce the variety domestically, $\varphi^{D}(\lambda)$, is increasing in $\lambda$, while (b) the 
minimum productivity cutoff to export the variety, $\varphi^{X}(\lambda)$, is decreasing in $\lambda$. Accordingly, the productivity range of firms selling only domestically, $\left[\varphi^{D}(\lambda), \varphi^{X}(\lambda)\right]$, falls as quality increases.

The reason why the two productivity cutoffs behave differently has to do with the assumption that an exporter has already incurred the fixed cost of developing variety $\lambda$ and so will export that variety if the additional net revenue from exporting covers the fixed cost of exporting. Since the additional revenue increases with quality, firms with lower productivity can profitably export higher quality varieties.

At the same time, it requires highly productive firms to export a low quality variety because low quality varieties do not raise enough demand and revenue to cover the fixed entry cost to export. Only those higher productive firms, which can produce each variety at a lower cost, are able to be profitable with exporting a lower quality variety. This implies that there is an increasingly fewer firms that can export lower quality varieties, and the share of exporters increase as the quality increases up to the export quality threshold $\lambda_{H}$.

Proposition 2 For high quality varieties such that $\lambda>\lambda_{H}$, (a) the minimum productivity cutoff to produce the variety domestically, $\varphi^{D}(\lambda)$, is increasing in $\lambda$, and (b) exceeds the minimum productivity cutoff to export the variety, i.e., $\varphi^{D}(\lambda)>\varphi^{X}(\lambda)$.

This proposition indicates that for high quality varieties, there is a low productivity range of firms, $\left[\varphi^{D}(\lambda), \varphi^{X}(\lambda)\right]$, that find it profitable to export even though they make a loss by selling domestically. By selling domestically, these firms incur the development cost of the product variety and are not productive enough to make a domestic profit. However, their export sales yield net profits, after paying the fixed and variable cost of exporting, that more than compensate for their domestic loss. Whether the required minimum productivity for the firm to export increases as product quality increases, depends on particular parameter settings as the following proposition shows.

Proposition 3 Assume that $\lambda_{H}<\lambda_{M}$.

(a) For high quality varieties such that $\lambda_{H}<\lambda<\lambda_{M}$, the productivity cutoff to export the variety, $\varphi^{H}(\lambda)$, is decreasing in $\lambda$. Accordingly, the productivity range of firms exporting increases as quality increases in this variety quality range.

(b) For high quality varieties such that $\lambda_{H}<\lambda_{M}<\lambda$, the productivity cutoff to export the variety, $\varphi^{H}(\lambda)$, is increasing in $\lambda$. Accordingly, the productivity range of firms exporting decreases as quality increases in this variety quality range. 
Assume that $\lambda_{H}>\lambda_{M}$.

(c) For high quality varieties such that $\lambda_{H}<\lambda$, the productivity cutoff to export the variety, $\varphi^{H}(\lambda)$, is increasing in $\lambda$. Accordingly, the productivity range of firms exporting decreases as quality increases in this variety quality range.

Proposition 3 compares the productivity cutoffs for domestic production and sales only and for also exporting product varieties. Part (b) of this proposition, in combination with Proposition 2, indicates that both productivity cutoff functions are increasing in product variety quality, $\lambda$, and that the domestic productivity cutoff function is higher than that for exporting. There is a range of productivities for which domestic production only would incur a loss, and for which exporting generates sufficient profit to outweigh this loss (Proposition 2). Moreover, both functions are increasing in $\lambda$, so that the productivity range for exporting varieties is decreasing in variety quality.

Figures 1 and 2 provide graphical illustrations of these three propositions. Each figure plots the productivity cutoff curves, with product quality, $\lambda$, on the horizontal axis and productivity, $\varphi$, on the vertical axis. Figure 1 illustrates the case where $\lambda_{M}<\lambda_{H}$, implying that $\varphi^{H}(\lambda)$ is increasing for all $\lambda>\lambda_{H}$. This figure shows the downward sloping and convex (Lemma 4) curve $\varphi^{L}(\lambda)$ above the upwards sloping and concave (Lemma 3) curve $\varphi^{d}(\lambda)$, which it intersects at the point $\left(\lambda_{H}, \varphi_{H}\right)$. Also shown is the upward sloping curve $\varphi^{H}(\lambda)$, which also passes through point $\left(\lambda_{H}, \varphi_{H}\right)$. Curves $\varphi^{L}(\lambda)$ and $\varphi^{X}(\lambda)$ form a $(\lambda, \varphi)$ region (coloured pink) in which firms of productivity $\varphi$ will export product variety $\lambda$. For any $(\lambda, \varphi)$ in the region above the curve $\varphi^{d}(\lambda)$, the firm will produce and sell domestically. The lower boundary of the pink region may be formally defined by $\varphi^{X}(\lambda) \equiv \max \left\{\varphi^{L}(\lambda), \varphi^{H}(\lambda)\right\}$, the minimum export productivity cutoff over all variety qualities, $\lambda$, shown as the solid red curve.

Figure 1 also indicates the implied quality ranges exported and sold domestically for a particular productivity level. Importantly, the pink region defined by lower boundary $\varphi^{X}(\lambda)$ has a V-shape. This means that as the productivity of a firm increases above $\varphi_{H}$, the quality ranges of varieties sold domestically and exported both increase. However, while all qualities are sold domestically, the export quality range has a minimum, which declines as productivity increases.

Figure 2 has a similar structure to Figure 1, but illustrates the case where $\lambda_{M}>\lambda_{H}$, implying that $\varphi^{H}(\lambda)$ is decreasing in variety quality when $\lambda_{H} \leqslant \lambda \leqslant \lambda_{M}$ and increasing in variety quality when $\lambda \geqslant \lambda_{M}$. The export productivity curve $\varphi^{H}(\lambda)$, which passes through point $\left(\lambda_{H}, \varphi_{H}\right)$, is shown to be decreasing for low product qualities beyond $\lambda_{H}$, reaching a minimum at $\lambda_{M}$ and then increasing for higher variety quality levels. The pink region showing the region over which firms of productivity $\varphi$ will export product 


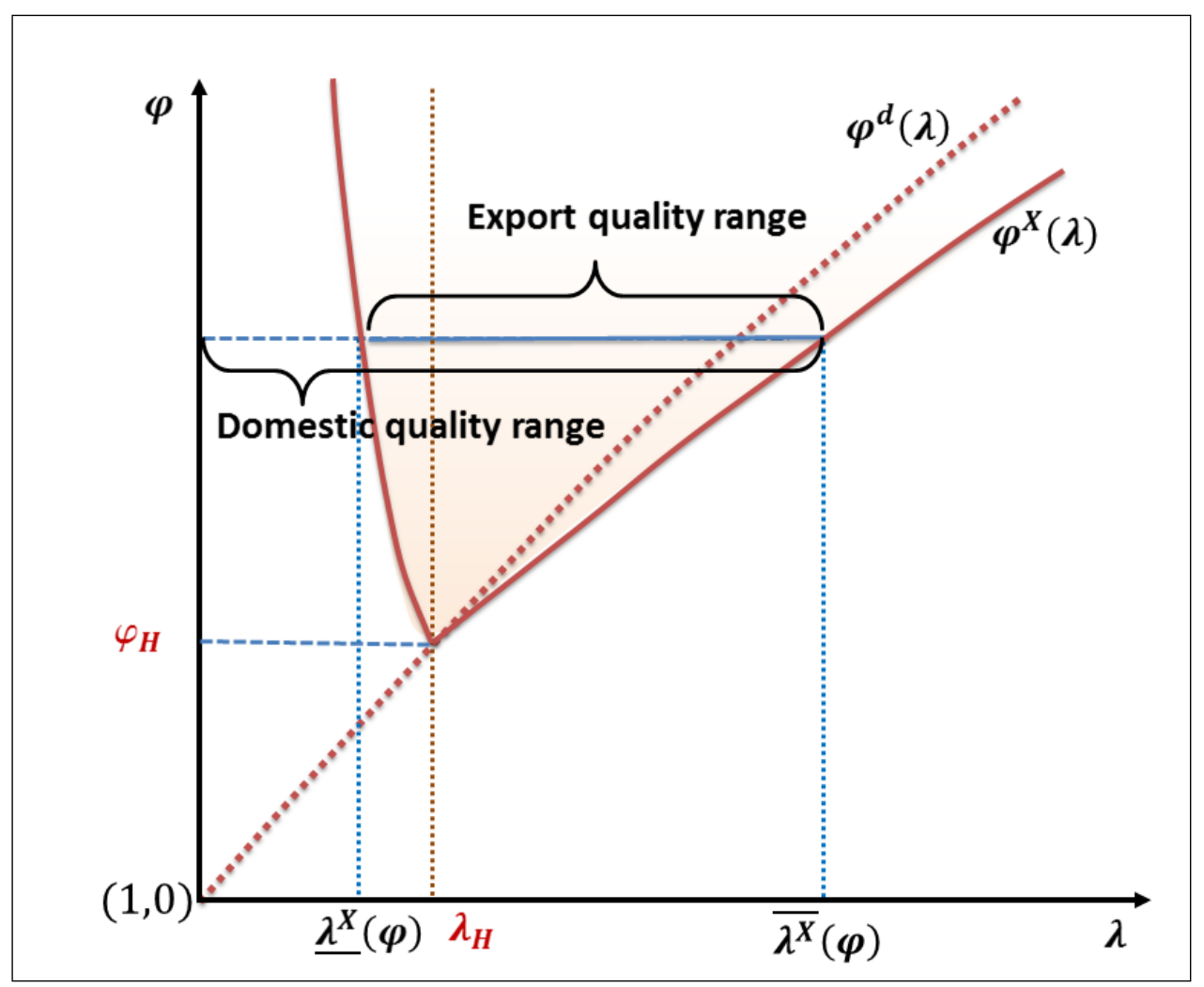

Figure 1: The export productivity cutoff when $\lambda_{M}<\lambda_{H}$

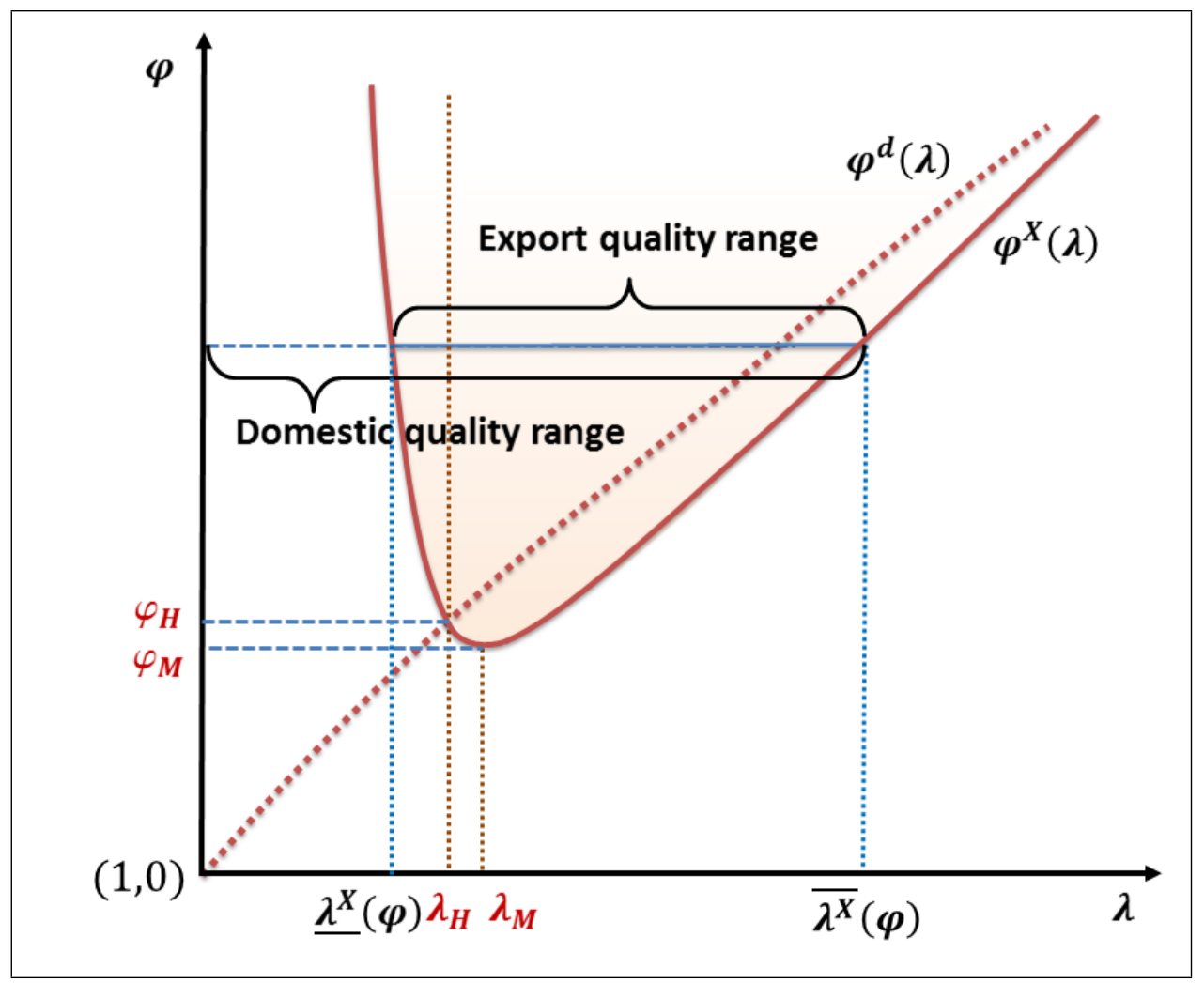

Figure 2: The export productivity cutoff when $\lambda_{M}>\lambda_{H}$ 
variety $\lambda$ now has a U-shape, with lower boundary given by the minimum productivity cutoff function $\varphi^{X}(\lambda)$. The variety quality yielding the minimum productivity needed to export is now given by $\lambda_{M}>\lambda_{H}$, which is the case depicted in Figure 2.

Thus, the general thrust of the results illustrated in the two figures is the same; the minimum productivity required to export falls with variety quality, reaches a minimum, and then increases as variety quality rises. Both figures show that (i) only more productive firms can export higher quality varieties (above the minimum of $\varphi^{X}(\lambda)$ ) and (ii) only more productive firms can export low quality varieties (below the minimum of $\varphi^{X}(\lambda)$ ).

An interesting implication of this falling export productivity curve $\varphi^{H}(\lambda)$ in Figure 2 is that for productivities between $\varphi_{M}$ and $\varphi_{H}$, there is a gap in the ranges of variety qualities produced domestically and exported; variety qualities in this gap are not produced. This gap in variety qualities falls as productivity increases and ceases to exist when $\varphi \geq \varphi_{H}$. Since the minimum productivity curve $\varphi^{X}(\lambda)$ falls and then rises with variety quality in the range $\lambda>\lambda_{H}$ in Figure 2, the productivity range for exporting activities at first rises and then, as in Figure 1, falls.

Further results and discussion The comments made above regarding the contents of Figures 1 and 2 may be summarized in the following corollaries, which are expressed from the viewpoint of the firm and its productivity rather than from the viewpoint of product quality.

Corollary 1 As the productivity level of a firm restricted to the domestic market increases, the quality range of varieties produced and sold domestically by the firm increases.

Corollary 2 If exporting by firms is permitted, there is a minimum productivity level that is required to export any quality variety.

Corollary 3 As productivity increases beyond this minimum productivity level required to export, the quality range that is exported increases and expands towards both ends of the quality ladder while the low-end quality range that is only sold domestically decreases. All exported quality varieties are also sold domestically.

Corollary 4 For any productivity level permitting exports, there is a range of highest quality varieties that are exported but that would not be profitable to produce if the firm was not permitted to export.

Our propositions and corollaries above get some support from the empirical literature. The finding in Corollary 3 that more productive firms are able to extend their export 
product range towards both ends of the quality ladder and, thus, have a wider range of export prices, is consistent with the empirical results from Manova \& Zhang (2012) that exporters that export more, enter more markets, offer a wider range of export prices and pay a wider range of input prices. It also finds support from the empirical results by Bhattarai \& Schoenle (2014), who found that the dispersion of within-firm price changes (both upward and downward price changes) is greater as the number of products supplied by a firm is larger.

The intuition behind Corollary 4 is that the chance to export gives a firm an incentive to invest in its quality, since the additional export revenue can compensate for the higher $\mathrm{R} \& \mathrm{D}$ investment required to produce higher quality products. This result is also in line with Bustos (2011), who suggests that firms will upgrade the technology of their products when the economy transits from autarky to open trade.

In addition, existing literature on multi-product firms and quality differentiation suggests an uniform product quality hierarchy across markets for each firm. Corollary 4 of our model suggests that such a product quality hierarchy is not the same in the domestic market and the export market given the ability of firms to upgrade their product quality in the export market. This result finds support from the empirical evidence by Fontagne et al. (2018) that firms export different combinations of product across markets with a substantial departure from a global product hierarchy, yet, there exists a stable component in firms product across destinations which are not necessarily the most important in terms of sales.

Finally, our model generates the result that revenue earned by selling domestically or in the export market is higher for higher quality product varieties. On the other hand, the model also generates the result that domestic and export quantities may be increasing or decreasing in quality depending on whether technology parameter $\beta$ is small or large. These results are formally stated as Proposition 7 and proved in the Appendix. The first result is in line with the empirical findings by Manova \& Yu (2017) that there is a positive correlation between price of a product and the rank of its export revenue within a firm. The second result, on the other hand, indicates that the top-end varieties have larger output sales if only the effective labour cost elasticity with respect to quality in the production technology is low, i.e., $\beta$ is low. When $\beta$ is high, the lower-end varieties would have larger sales. This finding is consistent with Eckel et al. (2015), which suggests that prices are positively correlated with sales when investment in quality is more effective. The answer for the best-performing products of a firm is, therefore, sensitive to the characteristics of the production technology. 


\section{Trade liberalization}

Introduction In this section, we analyze the effects of trade liberalization in our model. By trade liberalization, we mean a reduction in either the ad valorem trade cost (transport cost) or the fixed entry cost to the export market. In particular, we analyze the effect of a reduction in the iceberg trade transport cost, $\tau$, on the export productivity cutoffs and, thus, on a firms' export quality range.

The lowering of trade barriers has a well-known "creative destruction" effect on firms' export behaviour through higher productivity cutoffs to export and to survive in the domestic market (Melitz (2003)). This effect is a result of the higher level of competition under trade liberalization, which lowers the market share and profit for each firm and, hence, only the more productive firms can survive and only the most productive firms can export. This also suggests that trade liberalization benefits larger firms at the loss of smaller firms.

The effects of trade liberalization on the product range and quality choice of multiproduct firms have, however, been underemphasized in the literature. With the exception of Bernard et al. (2011), no multi-product firm model analyses have discussed the effects of trade liberalization on the product quality ranges of firms. Bernard et al. (2011) suggests that a decrease in the variable trade cost $\tau$ increases the share of firms that export and increases the share of products exported by existing exporters. Our purpose here is to address this issue in the context of our model. We show below that a reduction in the trade cost would have heterogeneous effects on the product quality range across firms.

Propositions regarding trade liberalization The following proposition demonstrates that trade liberalization in the form of a reduction in the unit trade cost will lead to different effects on productivities depending on the product variety quality.

Proposition 4 Under a reduction in the transport cost $\tau$ : (a) the domestic productivity cutoff $\varphi^{d}(\lambda)$ given by (20) decreases for all product variety qualities, i.e., $\frac{d}{d \tau} \varphi^{d}(\lambda)<0$, $\forall \lambda \in \Lambda$; and (b) the export productivity cutoff $\varphi^{X}(\lambda)$ given by (33) increases for all product variety qualities, i.e., $\frac{d}{d \tau} \varphi^{X}(\lambda)>0, \forall \lambda \in \Lambda$.

Proof. The proof is provided in the Appendix.

This proposition leads to the following proposition.

Proposition 5 Under a reduction in the transport cost $\tau$ : (a) the share of low-end exporters increases; (b) the domestic quality range of less productive, non-exporting firms, 
$\varphi<\varphi\left(\lambda_{H}\right)$, shrinks toward the lower end of the quality ladder; (c) the export quality range of more productive, exporting firms, $\varphi \geqslant \varphi\left(\lambda_{H}\right)$, expands toward both the lower end and the higher end of the quality ladder; (d) the quality ranges for new exporters that are less productive shrink toward the lower end of the quality ladder; and (e) the quality ranges for new exporters that are more productive expand toward the upper end of the quality ladder.

Proof. The proof is provided in the Appendix.

As $\tau$ decreases, there are more exporters and more varieties in the market, which lowers the price index $P$ and, hence, lowers the revenue and profit of every domestic firm. This is reflected through an increase in the domestic productivity cutoff given by (20). This effect is consistent with the standard Melitz (2003) result. In terms of the product range, the domestic quality upper bound for a firm, given by (22), is increasing in $\tau$, so it is lower under a lower $\tau$. This means that those domestic firms without an export opportunity, i.e., firms that can only produce the low quality product $\left(\varphi<\varphi\left(\lambda_{H}\right)\right)$, will see their product range shrink further toward the lower end quality varieties.

For exporting firms $\left(\varphi \geqslant \varphi\left(\lambda_{H}\right)\right)$, the productivity cutoff to produce and export a high quality variety $\left(\varphi^{X}(\lambda)=\varphi^{H}(\lambda), \lambda \geqslant \lambda_{H}\right)$ is lower under trade liberalization and so these firms can produce and export higher quality varieties. The export lower quality bound $\lambda^{X}$, given by the inverse of $\varphi^{X}(\lambda)$ defined in (33) over this low quality range, is also lower under a lower $\tau$, implying that a firm can export a lower-end variety under trade liberalization.

The effect of trade liberalization on the export ranges of firms is illustrated in Figure 3. This figure plots the domestic productivity cutoff and the export productivity cutoff functions before and after a reduction in the transport cost from $\tau$ to $\tau^{\prime}<\tau$. The dotted curves represent the domestic productivity cutoffs, and the smooth V-shaped curves represent the export productivity cutoff in two scenarios, the red colour referring to the high $\tau$ case and the blue colour referring to the low $\tau^{\prime}$ case. These productivity cutoff functions shift in accordance with Proposition 4, where a reduction in $\tau$ results in a higher domestic productivity cutoff but a lower export productivity cutoff at every quality level. The domestic productivity cutoff function shifts to the left, while the export productivity cutoff function shifts downwards. The export quality benchmark shifts to the left, from $\lambda_{H}$ to $\lambda_{H}^{\prime}$.

As can be seen from this figure, those least productive firms with no chance of exporting $\left(\varphi<\varphi_{H}^{\prime}\right)$ see their domestic product range shrink after trade liberalization. Relatively more productive firms that previously produced low-end products and that do not export $\left(\varphi_{H}^{\prime}<\varphi<\varphi_{H}\right)$ experience a lower export productivity cutoff under trade lib- 


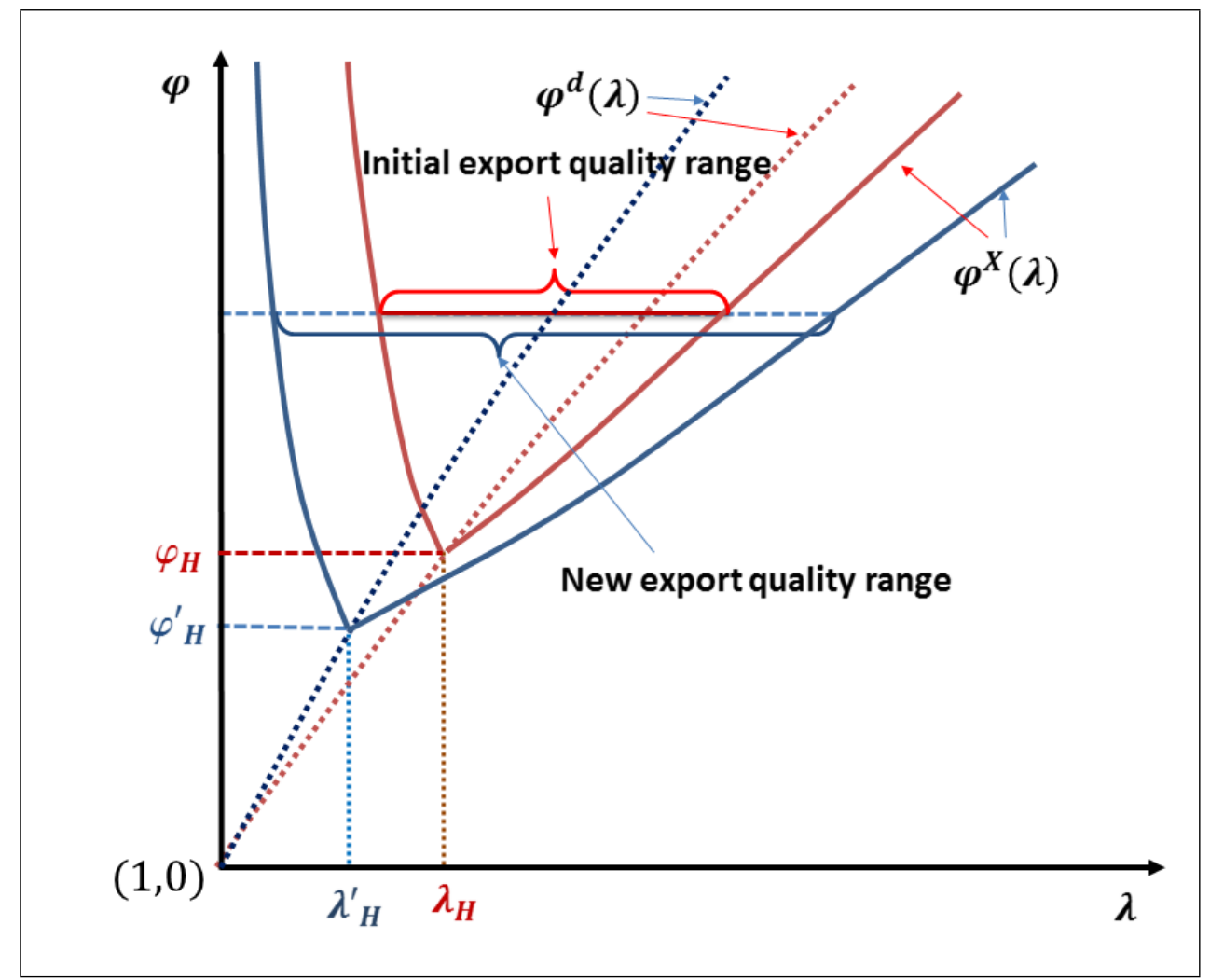

Figure 3: The export product range under trade liberalization

eralization, thus giving them a chance to enter the foreign market. Nevertheless, those firms with productivity close to $\varphi_{H}^{\prime}$ find that their product quality range shrinks, while only those firms with productivity close to $\varphi_{H}$ may observe an increased product quality range.

The export product quality ranges for existing exporters - the highly productive firms with $\varphi \geqslant \varphi_{H}$ - expand toward both the low-end and the high-end of the quality ladder, as shown in Figure 3 by the increase in the size of the braces (the blue one being larger). Once again, we can see that firms compete on both price and quality under trade liberalization. A lower trade cost raises a firm's export profit and allows it to make a larger $R \& D$ investment to raise its product quality. At the same time, a higher export profit at every quality level allows a highly productive firm to export its lower end products. With its low-cost advantage, the highly productive exporting firm can take away the market share from the less productive firms operating only on the domestic market. This result also shows that trade liberalization reallocates resources from the smallest firms to the largest firms. Moreover, it shows that more low-end quality products are now supplied by the large exporting firms, in addition to them supplying more to the high-end product quality market. 
Parts (d) and (e) of Proposition 5 indicate that new exporters have different effects on their quality ranges depending on their productivities. A reduction of trade cost from $\tau$ to $\tau^{\prime}<\tau$ allows firms with productivity in the range $\varphi_{H}>\varphi>\varphi_{H}^{\prime}$ to start exporting. For these new exporters, the highest quality that it can produce under the previous level of trade cost, $\tau$, is $\varphi^{d}(\lambda, \tau)$ while the highest level of quality it can produce and export under the new level of trade cost $\tau^{\prime}$ is $\varphi^{H}\left(\lambda, \tau^{\prime}\right)$. The ratio $\frac{\varphi^{H}\left(\lambda, \tau^{\prime}\right)}{\varphi^{d}(\lambda, \tau)}$ may be expressed as

$$
\frac{\varphi^{H}\left(\lambda, \tau^{\prime}\right)}{\varphi^{d}(\lambda, \tau)}=\frac{\varphi^{H}\left(\lambda, \tau^{\prime}\right)}{\varphi^{d}\left(\lambda, \tau^{\prime}\right)} \frac{\varphi^{d}\left(\lambda, \tau^{\prime}\right)}{\varphi^{d}(\lambda, \tau)}=\frac{\varphi^{H}\left(\lambda, \tau^{\prime}\right)}{\varphi^{d}\left(\lambda, \tau^{\prime}\right)} \frac{P(\tau)}{P\left(\tau^{\prime}\right)}=\left(\frac{1+\lambda^{-r} f_{x}}{1+\lambda_{H}^{\prime-r} f_{x}}\right)^{\frac{1}{\theta-1}} \frac{P(\tau)}{P\left(\tau^{\prime}\right)}
$$

In this expression, there are two component effects that move in opposite directions, i.e., the trade-induced innovation effect, $\frac{\varphi^{H}\left(\lambda, \tau^{\prime}\right)}{\varphi^{d}\left(\lambda, \tau^{\prime}\right)}$, and the trade-induced competition effect, $\frac{\varphi^{d}\left(\lambda, \tau^{\prime}\right)}{\varphi^{d}(\lambda, \tau)}$. It can be shown that the trade-induced competition effect is $\frac{\varphi^{d}\left(\lambda, \tau^{\prime}\right)}{\varphi^{d}(\lambda, \tau)}>1$, while the trade-induced innovation effect is $\frac{\varphi^{H}\left(\lambda, \tau^{\prime}\right)}{\varphi^{d}\left(\lambda, \tau^{\prime}\right)}<1$ for $\lambda>\lambda_{H}^{\prime}$. Accordingly, the product of these ratios, $\frac{\varphi^{H}\left(\lambda, \tau^{\prime}\right)}{\varphi^{d}(\lambda, \tau)}$, will be greater or less than unity depending on which of the two components dominate.

If the trade-induced innovation effect dominates the competition effect, then the ratio is less than unity. This means that the productivity cutoff to export a high quality product after the trade cost reduction is lower than the domestic productivity cutoff before the trade cost reduction. Therefore, firms can produce and export a higher quality product than before, i.e., there will be quality upgrading. On the other hand, if the tradeinduced competition effect dominates the innovation effect, then the ratio is greater than unity. This means that the productivity cutoff to export a high quality product after the trade cost reduction is higher than the domestic productivity cutoff before the trade cost reduction. Therefore, firms that can produce this product previously can no longer produce this variety at a lower trade cost. The quality range will shrink towards the lower end of the quality ladder. The proof (see Appendix) demonstrates that a firm with productivity greater than a specific value, $\varphi>\varphi^{*}\left(\tau, \tau^{\prime}\right)$, whether being an incumbent exporter or a new exporter, can upgrade its product quality range after the reduction in trade cost. A firm with productivity $\varphi<\varphi^{*}\left(\tau, \tau^{\prime}\right)$, whether being a new exporter or remaining as a domestic oriented firm, will drop its top quality varieties and contract its product quality range toward the lower-end after a reduction in trade cost.

To elaborate further on the effect of trade liberalization on the product quality ranges of firms, it is instructive to consider more deeply the responsiveness of the shifts in the export productivity cutoff function to the change in variable trade costs. To this end, we define the elasticity of the export productivity cutoffs with respect to the transport 
cost as

$$
E_{\tau, L}=\frac{d \ln \varphi^{X}(\lambda)}{d \ln \tau}, \quad \lambda<\lambda_{H}
$$

in the low quality range and at the high quality range as

$$
E_{\tau, H}=\frac{d \ln \varphi^{X}(\lambda)}{d \ln \tau}, \quad \lambda>\lambda_{H} .
$$

The following proposition establishes a clear relationship between these two elasticities.

Proposition 6 (a) The lower bound for the product quality range is more responsive to a change in $\tau$ than the upper bound for the product quality range, i.e., $E_{\tau, L}>E_{\tau, H}$.

(b) The responsiveness of the difference between the lower quality bound and the upper quality bound is increasing in the trade cost, $\tau$.

Proof. The proof is provided in the Appendix.

The result in the first part of Proposition 6 means that firms will extend more toward the lower end of the product quality range for export under trade liberalization than they will towards the upper end of the product quality range for export. This may be interpreted to mean that competition on price always dominates the competition on quality (in terms of the number of new varieties introduced).

The second part of the proposition shows how this effect of trade liberalization is influenced by the level of variable trade costs. Lower variable trade costs reduce the size of the relative effects of trade liberalization on the lower versus higher product quality boundary. Trade liberalization, therefore, encourages firms to invest and export higher quality products.

Discussion There is a large empirical literature about the heterogenous responses of firms toward trade liberalization that provides evidence supporting our findings. See, for example, Verhoogen (2008), Bustos (2011), Iacovone (2012), Iacovone et al. (2013), Amiti \& Khandelwal (2013) and Bloom et al. (2016). These studies suggest that trade liberalization encourages larger/more productive firms to upgrade their production technology and product quality while reducing the incentive to innovate for smaller and less productive firms.

Propositions 4 and 5 on the implications of trade liberalization for the quality ranges of firms find support from a number of empirical studies about the product scope of multiproduct firms. In particular, Baldwin \& Gu (2009) found that small or non-exporting Canadian firms reduce their product scope and their product diversification index when 
tariff is lower following Canada-US Free Trade Agreement. Iacovone \& Javorcik (2010) found that Mexican firms reduced product scope in the domestic market in sectors where there was a significant decline in Mexican tariffs following NAFTA. Iacovone \& Javorcik (2008) show that experienced exporters are more likely than new exporters to introduce into export markets varieties not previously sold domestically, which provides evidence that existing exporters are able to add more new varieties into their export product range compared to new exporters.

While these studies do not discuss product quality, their findings are consistent with Proposition 4(a), Proposition 5(b) and Proposition 5(d) in the sense that the product ranges of non-exporting firms and small exporting firms are narrowed in response to a trade cost reduction. On the other hand, Proposition 4(b) and Proposition 5(c) suggest that the export productivity cutoff decreases for all product varieties and that the export product range of existing exporters increases. This result is in line with empirical findings from Berthou \& Fontagne (2013) that trade liberalization following the introduction of the euro induce firms in the highest quartile to increase their exports and their export product scope, and findings from Iacovone \& Javorcik (2010) that after the tariff cuts following NAFTA, the number of products exported by Mexican firms increased and existing Mexican exporters increase their product varieties by more than new exporters.

Regarding product quality differentiation, Proposition 5 suggests that existing exporters and more productive new exporters are able to upgrade their product quality and add varieties of higher quality to their export product ranges, while less productive firms must narrow down their product ranges toward the lower quality varieties in response to trade liberalization. These findings about the heterogenous response of firms are in line with a number of empirical studies which suggest that more productive firms tend to invest more on upgrading their products compared to less productive firms. Verhoogen (2008), for example, finds that after the peso devaluation more productive Mexican plants increased their export sales, skilled wages, ISO 9000 quality certifications more than less-productive plants. Bustos (2011) finds a link between a fall in tariffs and increases in technology spending by more productive Argentinian exporters. Iacovone (2012) shows that trade liberalization following NAFTA boosted innovation efforts by more productive firms while it weakened the incentive to innovate for less productive firms. Bloom et al. (2016) shows that increasing Chinese import competition led to increases in R\&D, patenting, IT spending within firms and increased employment in more innovative and technologically advanced firms, while it reduces employment and survival probabilities in low-tech firms. 


\begin{tabular}{ll}
\hline \hline Parameters & Value \\
\hline World quality frontier & $\bar{\lambda}=30$ \\
National income & $Y=500$ \\
Productivity distribution's scale parameter & $\varphi_{m}=1$ \\
Productivity distribution's shape parameter & $k=4$ \\
Wage rate & $w=1$ \\
Fixed entry cost to export & $f_{X}=10$ \\
Elasticity of substitution & $\theta=3$ \\
R\&D inefficiency parameter & $r=3$ \\
Iceberg transportation cost factor & $\tau=3$ \\
Technology quality intensity parameter & $\beta=0.4$ \\
\hline \hline
\end{tabular}

Table 1: Parameter values for base model

\section{$5 \quad$ Numerical Illustration}

This section provides a numerical simulation to support our propositions about the effects of trade liberalization (which refers now solely to a reduction in the transportation cost $\tau)$ on the productivity cutoff to export, and thus, the behaviour of exporters at each level of product quality. The assumed numerical values for the model's parameters are presented in Table 1.

Figure 4 plots various productivity cutoff functions for the base model with parameters given in Table 1 on a graph with quality levels on the horizontal axis and firm's productivity on the vertical axis when quality runs from 1 to 30 and productivity runs from 1 to 20. First, the productivity cutoff function $\varphi^{L}(\lambda)$ is shown as the downward sloping red curve continued as a black dotted curve. The upward sloping solid blue curve depicts $\varphi^{d}(\lambda)$, while the black dotted curve continuing as the upward sloping red curve depicts $\varphi^{H}(\lambda)$. It is noted that the minimum of this curve is to the left of the intersection point at $\lambda_{H} \approx 3.5$. Second, we plot $\varphi^{X}(\lambda)$ as the solid red curve comprising two parts. For low qualities such that $\lambda<\lambda_{H}, \varphi^{X}(\lambda)=\varphi^{L}(\lambda)$ is the downward sloping part of the solid red curve; for high qualities such that $\lambda>\lambda_{H}, \varphi^{X}(\lambda)=\varphi^{H}(\lambda)$ is the upward sloping part of the solid red curve. We then examine the change to this figure when there is a change in the variable trade cost $\tau$.

Given this initial base model situation, we now examine the effects on the cutoff functions and the equilibrium outcomes when there is a change in the variable trade cost $\tau$. Figure 5 shows how the domestic productivity cutoff and the export productivity cutoff functions change when the trade cost $\tau$ decreases from $\tau=3$ (the green curves) to $\tau=2$ (the red curves) then to $\tau=1$ (the blue curves). Consistent with the analysis in Section 4 , the figure shows that the productivity cutoffs to export both low-end products and 


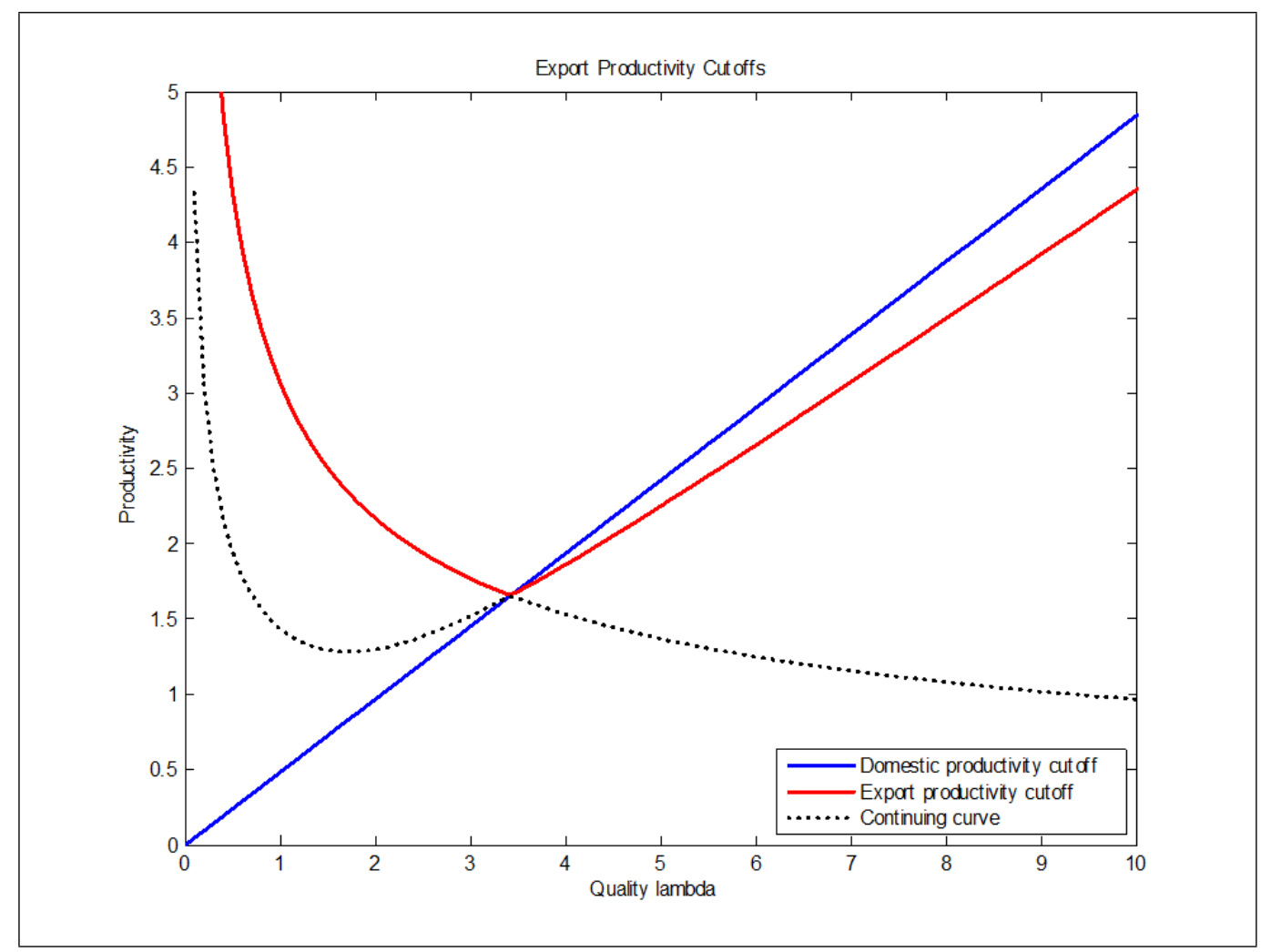

Figure 4: The export productivity cutoffs by quality

high-end products decreases, while the domestic productivity cutoff increases as trade costs fall. It can be seen that when the trade cost decreases, the productivity cutoff to export the low quality varieties decreases significantly, while the productivity cutoff to export the high quality varieties slightly decreases. These changes result in an expansion of the export product range toward both ends of a certain exporter, but more toward the low-end products under trade liberalization. These effects illustrate our propositions regarding trade liberalization.

It is also shown in Figure 5 that there is an increasing gap between the domestic productivity cutoff curve (the dotted line) and the high-quality export productivity cutoff curve (the right branch of the $\mathrm{V}$-shaped smooth curve) as the transport cost $\tau$ gets smaller and as productivity gets higher. This suggests that trade liberalization with its increasing competition level makes it harder for firms to serve the domestic market only, and encourages firms to invest to produce and export higher quality products. This effect of trade liberalization on the development of new higher-end products is strongest in the top productive firms. More productive firms have more capacity to invest in their product quality and are more motivated to compete on quality compared to less productive firms. The price competition effect is, whereas, strongest in the less 


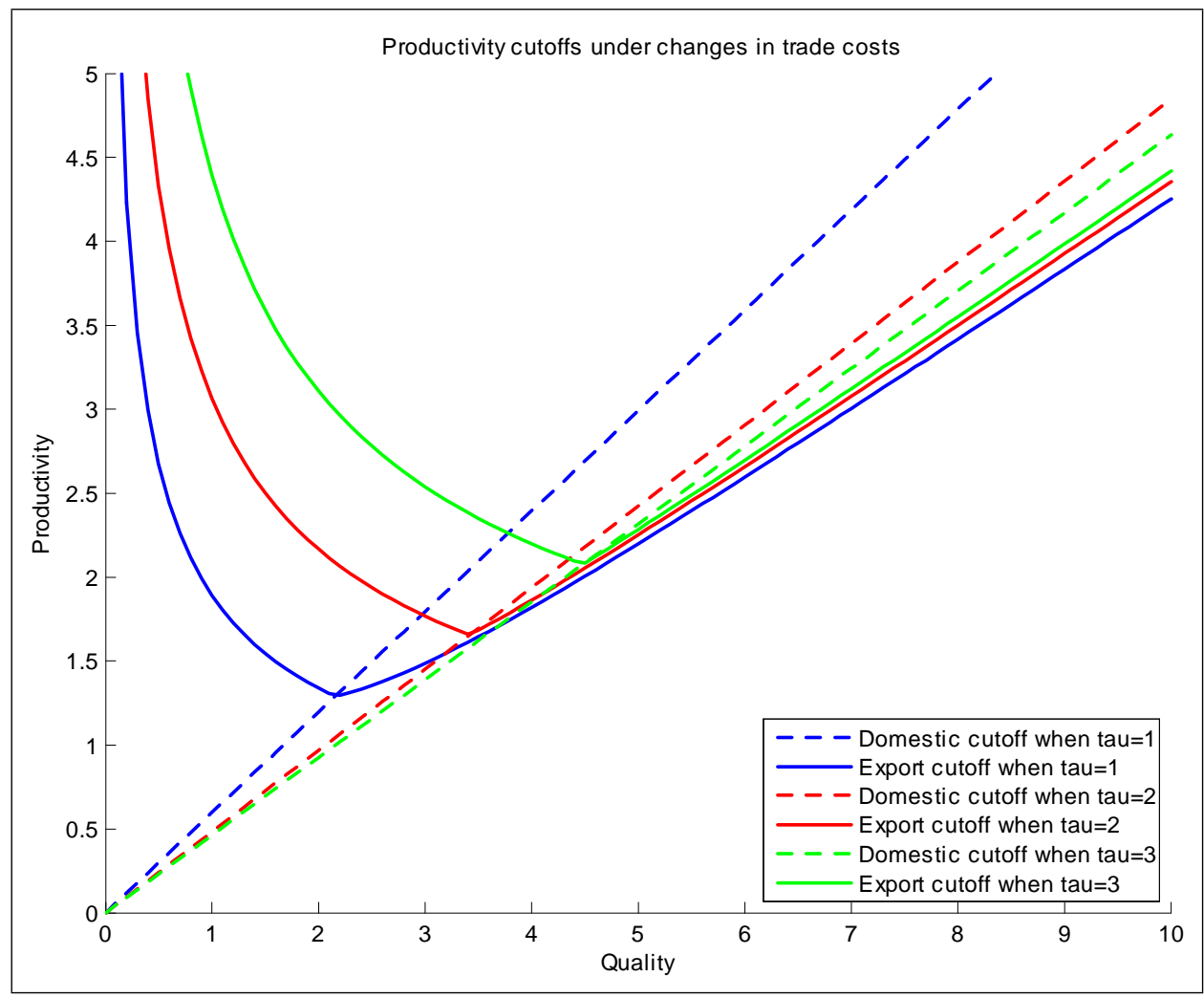

Figure 5: The export productivity cutoff under trade liberalization

productive firms. For example, a firm with $\varphi=1.4$ in the above numerical illustration has its product range shrunk toward the lower-end products when $\tau$ decreases from 2 to 1 .

Sensitivity analysis We undertake a limited sensitivity analysis of trade liberalization effects to some of the model parameters. First, we examine the effect of a reduction in the transportation cost on the productivity cutoffs to survive and export when the productivity profile of labour in the production of different variety qualities, measured by parameter $\beta$ in (7), changes. In Figure 6 , the left panel is the case where the elasticity of marginal labour cost with respect to quality is relatively low $(\beta=0.4)$, and the right panel demonstrates the case of a production technology in which the cost-quality profile is steeper $(\beta=0.7)$. In both cases, we consider a reduction of the transportation cost $\tau$ from 2 to 1 , and its effect on the productivity cutoffs, marked in red when $\tau=2$ and marked in blue when $\tau=1$. In the left panel (the lower cost-quality elasticity case), the right branches of the two export productivity cutoff curves before and after the trade cost reduction are almost coincident. This means that there is almost no change in the productivity cutoff to export high quality goods, thus limiting competition on quality. Under this relatively lower cost-quality elasticity technology, firms mostly compete on 


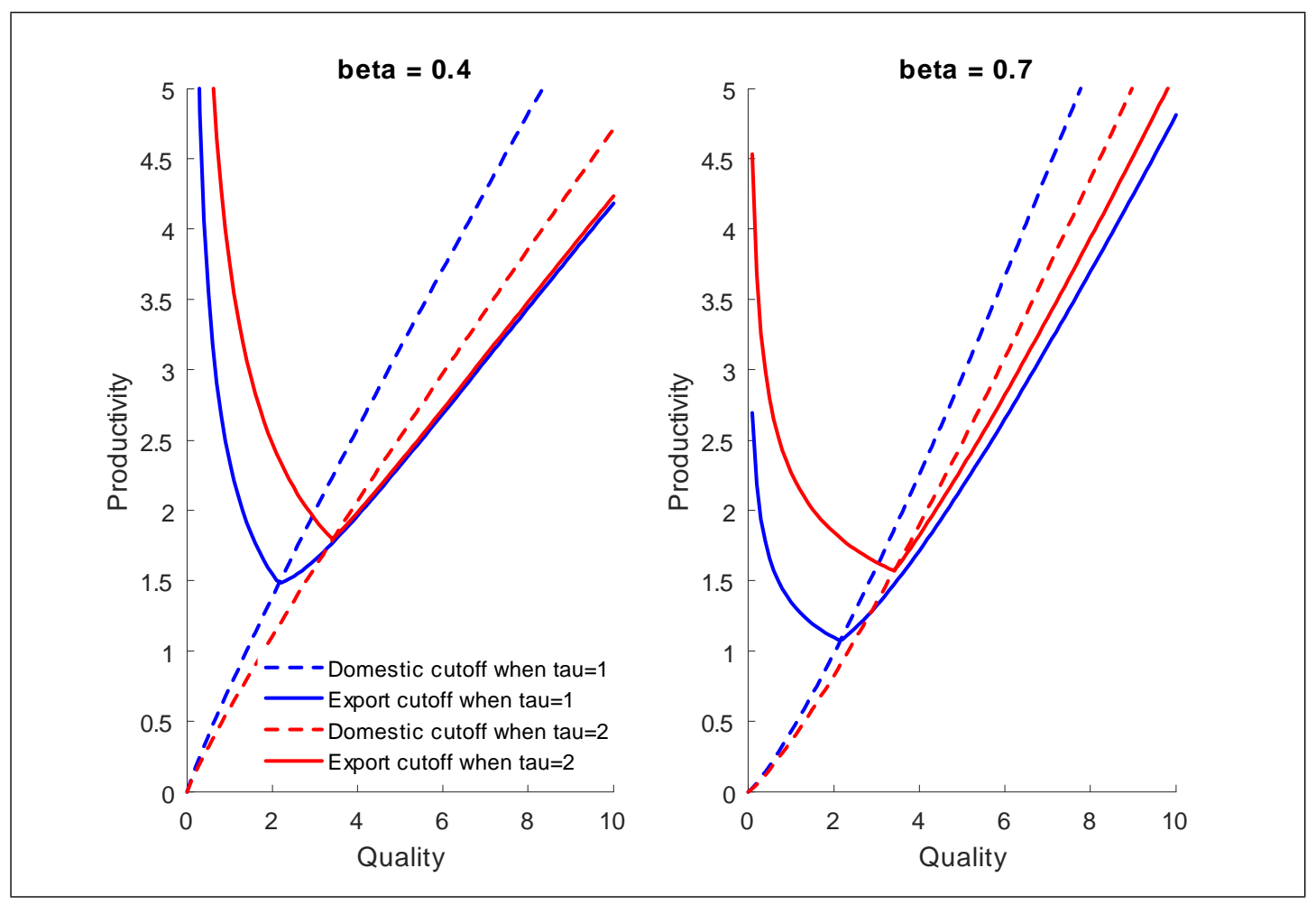

Figure 6: Trade liberalization effect and production technology

price. On the other hand, the distance between the productivity cutoffs to export high quality goods in the high trade cost case (the red curve) and the low trade cost case (the blue curve) is quite pronounced in the right panel $(\beta=0.7)$. This result adds to Proposition 6 by suggesting that firms will compete more on quality in the case where there is a technology with a relatively higher cost-quality elasticity.

Second, though not depicted here, we also numerically examined the effects on the export cutoffs with respect to trade costs of different settings for the fixed export cost, $f_{x}$, and the investment effectiveness parameter, $r$, indicating the extent to which fixed investment cost rises with the quality of the product variety. As $r$ increases, i.e., as it is more costly in terms of fixed investment to raise quality, $\lambda$, the gap between the right branches of the V-shaped export productivity cutoff curves is larger. This suggests a larger decrease in the export productivity cutoff for high quality range, or larger room for quality competition. The gap between the dotted lines (the domestic productivity cutoff) gets getting smaller, suggesting a lower competition effect on price. Similarly, as $f_{x}$ increases, i.e., as the fixed cost to export is higher, the gap between the right branches of the $\mathrm{V}$-shape curves is larger, implying that firms also compete relatively more on quality than on price. These numerical results further add to Proposition 6 by suggesting that firms will compete more on quality in the cases where there are relatively 
higher fixed export costs and where the fixed cost of innovation rises more quickly with quality. $^{2}$

\section{Conclusion}

This paper addresses a new question about the response of multi-product firms, which can differentiate their product quality, to trade liberalization. In doing so, it helps to unite two rather separated branches of literature in international trade, i.e., the product vertical differentiation literature and the product horizontal differentiation literature. The paper develops and analyzes a model of international trade in which multiproduct firms have heterogeneous productivities and can produce varieties distinguished by quality. Quality is valued by consumers, but incurs fixed and variable costs for the firms. Within this context, the paper develops results concerning the ranges of quality that firms produce in equilibrium and how these ranges are affected by productivity.

Particular focus is placed on the implications of trade liberalization for the quality ranges of varieties produced by multiproduct firms in both domestic and export markets. It is established in the product vertical differentiation literature that firms compete on quality and succeed with their higher quality products in the export market. In the product horizontal differentiation literature, on the other hand, firms compete on price and their core export products are their cheapest ones. By introducing the V-shaped export productivity cutoff by quality, we suggest that more productive firms can compete on both price and quality by exporting both higher-end and lower-end products compared to less productive firms.

Our focus on firms' adjustment of their product quality range in response to trade liberalization distinguishes our paper from the few existing studies of multi-product firms and quality differentiation. Trade liberalization leads to greater competition on price but also to more room for quality upgrading. Under a reduction in trade costs, large firms gain a larger share in both high-end and low-end markets, while smaller firms lose their market share and have to operate in the low-end market with a narrower product range. New exporters also experience this reallocation of market share, where more productive new exporters can expand their product quality range while less productive new exporters narrow down their product quality range toward the lower-end of the quality ladder.

Trade liberalization encourages exporters to both improve the quality and lower the prices of their export products. Nevertheless, a reduction in trade costs alone induces

\footnotetext{
${ }^{2}$ Graphical results for these two numerical experiments are available from the authors by request.
} 
exporters to sell more lower-end products in relative to higher-end products, since it is a low-cost strategy to gain extra profit in the foreign market. This strategy is sensitive to the trade cost level. Particularly, we can see a greater improvement in the quality of the export products and more firms invest to improve the quality of their product if trade liberalization occurs at a lower level of trade cost. 


\section{Appendix: Proofs}

\section{A.1 Lemmas}

Lemma 3 The profit cutoff function $\varphi^{d}(\lambda)$, indicating the productivity level yielding zero domestic profit, is increasing in $\lambda$ for all $\lambda \in \Lambda$ if $r>\gamma$ (condition (21) holds with strict inequality).

Proof. (Lemma 3) Using expression (20) for $\varphi^{d}(\lambda)$, it follows that its derivative is $\varphi^{d}(\lambda)=\frac{r-\gamma}{\theta-1} \kappa^{\frac{1}{1-\theta}} \lambda^{\left(\frac{r-\gamma}{\theta-1}-1\right)}>0$ since $r-\gamma>0$ and $\theta-1>0$ by assumption. Thus, $\varphi^{d}(\lambda)$ is increasing in $\lambda$.

Lemma 4 The profit cutoff function $\varphi^{L}(\lambda)$, indicating the productivity level that equates domestic and export profits, is decreasing and convex in $\lambda$ for all $\lambda \in \Lambda$.

Proof. (Lemma 4) Using expression (25) for $\varphi^{L}(\lambda)$, it follows that its derivative is $\varphi^{d \prime}(\lambda)=(\beta-1) \lambda^{\beta-2} k_{L}<0$ since $\beta-1<0$ by assumption and where $k_{L} \equiv \tau\left(\frac{f_{x}}{\kappa}\right)^{\frac{1}{\theta-1}}>0$. Similarly, the second derivative is $\varphi^{d \prime \prime}(\lambda)=(\beta-1)(\beta-2) \lambda^{\beta-3} k_{L}>0$ since $\beta-1<0$ by assumption. Thus, $\varphi^{L}(\lambda)$ is decreasing and convex in $\lambda$.

Lemma 5 The profit cutoff function $\varphi^{H}(\lambda)$, indicating the productivity level yielding zero export profit, has a unique minimum at $\lambda=\lambda_{M}$, where

$$
\lambda_{M}=\left[\frac{\gamma f_{x}}{r-\gamma}\right]^{\frac{1}{r}} .
$$

Proof. (Lemma 5) Expression (26) for $\varphi^{H}(\lambda)$ may be rewritten as $\varphi^{H}(\lambda)=k_{H} \lambda^{\beta-1}\left(\lambda^{r}+f_{x}\right)^{\frac{1}{\theta-1}}$, where $k_{H} \equiv\left[\kappa\left(1+\tau^{1-\theta}\right)\right]^{\frac{1}{1-\theta}}>0$. Its derivative is

$$
\begin{aligned}
\varphi^{H \prime}(\lambda) & =(\beta-1) \lambda^{\beta-2} k_{H}\left(\lambda^{r}+f_{x}\right)^{\frac{1}{\theta-1}}+k_{H} r \lambda^{\beta-1} \lambda^{r-1} \frac{1}{\theta-1}\left(\lambda^{r}+f_{x}\right)^{\frac{1}{\theta-1}-1} \\
& =\left((\beta-1)+r \frac{1}{\theta-1} \lambda^{r}\left(\lambda^{r}+f_{x}\right)^{-1}\right) k_{H}\left(\lambda^{r}+f_{x}\right)^{\frac{1}{\theta-1}} \lambda^{\beta-2} .
\end{aligned}
$$

Setting $\varphi^{H}(\lambda)=0$ and solving for $\lambda$, we find that the function $\varphi^{H}(\lambda)$ has a unique stationary point given by

$$
\lambda_{M}=\left(\frac{\gamma}{r-\gamma} f_{x}\right)^{\frac{1}{r}}
$$


The second derivative at the point $\lambda=\lambda_{H}$ is derived as

$$
\left.\varphi^{H \prime \prime}(\lambda)\right|_{\lambda=\lambda_{H}}=\left.\frac{k_{H}}{\theta-1} r^{2} f_{x} \lambda^{r+\beta-3}\left(\lambda^{r}+f_{x}\right)^{\frac{3-2 \theta}{\theta-1}}\right|_{\lambda=\lambda_{H}}>0 .
$$

Being positive the second order sufficiency condition for $\lambda=\lambda_{M}$ to be a minimum point is satisfied. Thus, $\varphi^{H}(\lambda)$ has a unique minimum at $\lambda=\lambda_{M}$. This implies that $\varphi^{H}(\lambda)$ is pseudoconvex.

Lemma 6 The profit cutoff function $\varphi^{H}(\lambda)$ is decreasing for all $\lambda<\lambda_{M}$ and is increasing for all $\lambda>\lambda_{M}$.

Proof. (Lemma 6) The first derivative of $\varphi^{H}(\lambda)$ may be expressed as

$$
\begin{aligned}
\varphi^{H \prime}(\lambda) & =\left((\beta-1)+r \frac{1}{\theta-1} \lambda^{r}\left(\lambda^{r}+f_{x}\right)^{-1}\right) k_{H}\left(\lambda^{r}+f_{x}\right)^{\frac{1}{\theta-1}} \lambda^{\beta-2} \\
& =\left[(\beta-1)(\theta-1)\left(\lambda^{r}+f_{x}\right)+r \lambda^{r}\right] k_{H}\left(\lambda^{r}+f_{x}\right)^{\frac{1}{\theta-1}-1} \lambda^{\beta-2} \frac{1}{\theta-1} \\
& =\left[-\gamma\left(\lambda^{r}+f_{x}\right)+r \lambda^{r}\right] k_{H}\left(\lambda^{r}+f_{x}\right)^{\frac{1}{\theta-1}-1} \lambda^{\beta-2} \frac{1}{\theta-1} \\
& =\left[\lambda^{r}-\lambda_{M}^{r}\right](r-\gamma) k_{H}\left(\lambda^{r}+f_{x}\right)^{\frac{1}{\theta-1}-1} \lambda^{\beta-2} \frac{1}{\theta-1} .
\end{aligned}
$$

Accordingly, $\varphi^{H^{\prime}}(\lambda)>0$ for $\lambda>\lambda_{M}$ and $\varphi^{H^{\prime}}(\lambda)<0$ for $\lambda<\lambda_{M}$.

Proof. (Lemma 1) First, the proofs for the inequalities between $\varphi^{H}$ and $\varphi^{L}$ are straightforward since $\varphi^{H}$ is upwards sloping, $\varphi^{L}$ is downward sloping and they pass through the point $\left(\lambda_{H}, \varphi_{H}\right)$. As a result, $\varphi^{L}(\lambda)>\varphi^{H}(\lambda)$ when $\lambda<\lambda_{H}$ and $\varphi^{L}(\lambda)<\varphi^{H}(\lambda)$ when $\lambda>\lambda_{H}$. Second, consider the ratio $\varphi^{d} / \varphi^{H}$, which may be expressed as

$$
\varphi^{d} / \varphi^{H}=\left(\frac{\lambda^{r}}{\lambda^{r}+f_{x}}\right)^{\frac{1}{\theta-1}}\left(1+\tau^{1-\theta}\right)^{\frac{1}{\theta-1}} .
$$

This ratio equals 1 when $\lambda=\lambda_{H}$. When $\lambda>\lambda_{H}, \frac{\lambda^{r}}{\lambda^{r}+f_{x}}>\frac{\lambda_{H}^{r}}{\lambda_{H}^{r}+f_{x}}$ and so the right hand side of (A.2) exceeds 1. The opposite inequality occurs when $\lambda<\lambda_{H}$. Thus, the inequalities between $\varphi^{d}$ and $\varphi^{H}$ have been proved.

Proof. (Lemma 2) First, consider $\varphi^{X}(\lambda)=\max \left\{\varphi^{L}(\lambda), \varphi^{H}(\lambda)\right\}$. From Lemma 1, $\varphi^{L}(\lambda)>\varphi^{H}(\lambda)$ and so $\varphi^{X}(\lambda)=\varphi^{L}(\lambda)$ when $\lambda<\lambda_{H}$. Also, $\varphi^{L}(\lambda)<\varphi^{H}(\lambda)$ and so $\varphi^{X}(\lambda)=\varphi^{H}(\lambda)$ when $\lambda>\lambda_{H}$. Second, consider $\varphi^{D}(\lambda)=\min \left\{\varphi^{d}(\lambda), \varphi^{H}(\lambda)\right\}$. From Lemma $1, \varphi^{d}(\lambda)<\varphi^{H}(\lambda)$ and so $\varphi^{D}(\lambda)=\varphi^{d}(\lambda)$ when $\lambda<\lambda_{H}$. Also, $\varphi^{d}(\lambda)>\varphi^{H}(\lambda)$ and so $\varphi^{D}(\lambda)=\varphi^{H}(\lambda)$ when $\lambda>\lambda_{H}$. 
Lemma 7 The closed-form expression for the price index given in (38) is

$$
P(\tau)=\frac{1}{\rho}\left(\frac{k \varphi_{m}^{k}}{k-\theta+1}\right)^{-\frac{1}{k}}\left(\frac{Y}{\theta}\right)^{\frac{\theta-1-k}{k(\theta-1)}} T(\tau)^{-\frac{1}{k}}
$$

where

$$
\begin{aligned}
T(\tau) & =\int_{1}^{\lambda_{H}}\left[\lambda^{\frac{r(\theta-1-k)}{\theta-1}}+f_{x} \lambda_{H}^{\frac{-r k}{\theta-1}}\right] \lambda^{k(1-\beta)} d \lambda \\
& +\left(1+\tau^{1-\theta}\right)^{\frac{k}{\theta-1}} \int_{\lambda_{H}}^{\bar{\lambda}}\left[\lambda^{r}+f_{x}\right]^{\frac{\theta-1-k}{\theta-1}} \lambda^{k(1-\beta)} d \lambda .
\end{aligned}
$$

Proof. The price index $P$, given by (38), and repeated for convenient as as

$$
P=\frac{1}{\rho} Z(\tau)^{\frac{1}{1-\theta}}=\frac{1}{\rho}\left[\frac{k \varphi_{m}^{k}}{k-\theta+1} \int_{1}^{\bar{\lambda}} \lambda^{\gamma}\left[\varphi^{D}(\lambda)^{\theta-1-k}+\tau^{1-\theta} \varphi^{X}(\lambda)^{\theta-1-k}\right] d \lambda\right]^{\frac{1}{1-\theta}}
$$

is a function of the transport cost, $\tau$, which affects the minimum productivity levels to produce and export. Using the productivity cutoff rules (33) and (34), $P$ can be rewritten as

$$
P=\frac{1}{\rho}\left(\frac{k \varphi_{m}^{k}}{k-\theta+1}\right)^{\frac{1}{1-\theta}}\left[\begin{array}{c}
\int_{1}^{\lambda_{H}} \lambda^{\gamma}\left[\varphi^{d}(\lambda)^{\theta-1-k}+\tau^{1-\theta} \varphi^{L}(\lambda)^{\theta-1-k}\right] d \lambda \\
+\int_{\lambda_{H}}^{\bar{\lambda}} \lambda^{\gamma} \varphi^{H}(\lambda)^{\theta-1-k}\left(1+\tau^{1-\theta}\right) d \lambda
\end{array}\right]^{\frac{1}{1-\theta}}
$$


Using the expressions of $\varphi^{d}(\lambda), \varphi^{L}(\lambda)$ and $\varphi^{H}(\lambda)$, given by (20), (25) and (26), $P$ becomes

$$
\begin{aligned}
P^{1-\theta}=\frac{1}{\rho}\left(\frac{k \varphi_{m}^{k}}{k-\theta+1}\right)\left[\begin{array}{c}
\int_{1}^{\lambda_{H}} \lambda^{\gamma}\left[\left(\kappa^{\frac{1}{1-\theta}} \lambda^{\frac{r-\gamma}{\theta-1}}\right)^{\theta-1-k}+\tau^{1-\theta}\left(\tau f_{x}^{\frac{1}{\theta-1}} \kappa^{\frac{1}{1-\theta}} \lambda^{\beta-1}\right)^{\theta-1-k}\right] d \lambda \\
+\left(1+\tau^{1-\theta}\right) \int_{\lambda_{H}}^{\lambda} \lambda^{\gamma}\left(\left[\frac{\lambda^{r}+f_{x}}{\kappa\left(1+\tau^{1-\theta}\right)}\right]^{\frac{1}{\theta-1}} \lambda^{\beta-1}\right)^{\theta-1-k} d \lambda
\end{array}\right] \\
=\rho^{\theta-1} \frac{k \varphi_{m}^{k}}{k-\theta+1}\left[\begin{array}{c}
\kappa^{\frac{\theta-1-k}{1-\theta}} \int_{1}^{\lambda_{H}} \lambda^{\gamma}\left[\lambda^{\frac{(r-\gamma)(\theta-1-k)}{\theta-1}}+\tau^{-k}\left(f_{x}^{\frac{1}{\theta-1}} \lambda^{\beta-1}\right)^{\theta-1-k}\right] d \lambda \\
+\left(1+\tau^{1-\theta}\right)^{\frac{-k}{1-\theta}} \kappa^{\frac{\theta-1-k}{1-\theta}} \int_{\lambda_{H}}^{\bar{\lambda}} \lambda^{\gamma}\left(\left[\lambda^{r}+f_{x}\right]^{\frac{1}{\theta-1}} \lambda^{\beta-1}\right)^{\theta-1-k} d \lambda
\end{array}\right] \\
=\rho^{\theta-1} \frac{k \varphi_{m}^{k}}{k-\theta+1} \kappa^{\frac{\theta-1-k}{1-\theta}}\left[\begin{array}{l}
\int_{1}^{\lambda_{H}}\left[\lambda^{\gamma+\frac{(r-\gamma)(\theta-1-k)}{\theta-1}}+\tau^{-k} f_{x}^{\frac{\theta-1-k}{\theta-1}} \lambda^{\gamma+(\beta-1)(\theta-1-k)}\right] d \lambda \\
+\left(1+\tau^{1-\theta}\right)^{\frac{-k}{1-\theta}} \int_{\lambda_{H}}^{\bar{\lambda}}\left[\lambda^{r}+f_{x}\right]^{\frac{\theta-1-k}{\theta-1}} \lambda^{\gamma+(\beta-1)(\theta-1-k)} d \lambda
\end{array}\right] \\
=\rho^{\theta-1} \frac{k \varphi_{m}^{k}}{k-\theta+1} \kappa^{\frac{\theta-1-k}{1-\theta}}\left[\begin{array}{c}
\int_{1}^{\lambda_{H}}\left[\lambda^{\frac{r(\theta-1-k)+\gamma k}{\theta-1}}+\tau^{-k} f_{x}^{\frac{\theta-1-k}{\theta-1}} \lambda^{k(1-\beta)}\right] d \lambda \\
\left.+\left(1+\tau^{1-\theta}\right)^{\frac{-k}{1-\theta}} \int_{\lambda_{H}}^{\bar{\lambda}}\left[\lambda^{r}+f_{x}\right]^{\frac{\theta-1-k}{\theta-1}} \lambda^{k(1-\beta)} d \lambda\right] .
\end{array}\right.
\end{aligned}
$$

Given that $\kappa=\frac{Y}{\theta}(\rho P)^{\theta-1}$, we have

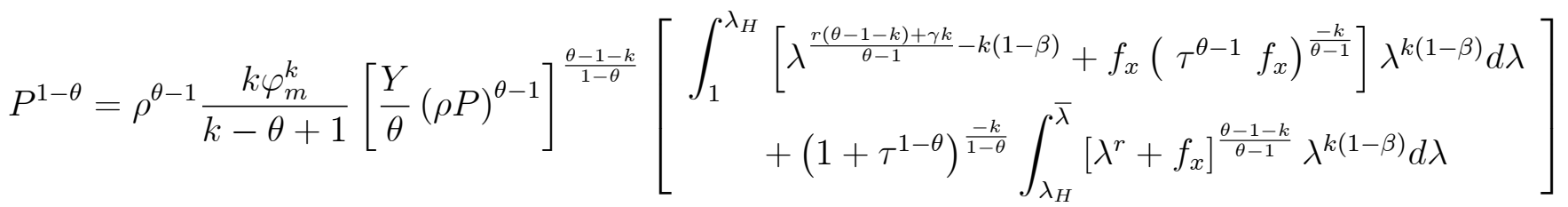

$$
\begin{aligned}
& P^{-k}=\rho^{k} \frac{k \varphi_{m}^{k}}{k-\theta+1}\left(\frac{Y}{\theta}\right)^{\frac{\theta-1-k}{1-\theta}}\left[\begin{array}{c}
\int_{1}^{\lambda_{H}}\left[\lambda^{\frac{r(\theta-1-k)}{\theta-1}}+f_{x} \lambda_{H}^{\frac{-r k}{\theta-1}}\right] \lambda^{k(1-\beta)} d \lambda \\
+\left(1+\tau^{1-\theta}\right)^{\frac{-k}{1-\theta}} \int_{\lambda_{H}}^{\bar{\lambda}}\left[\lambda^{r}+f_{x}\right]^{\frac{\theta-1-k}{\theta-1}} \lambda^{k(1-\beta)} d \lambda
\end{array}\right] \text {. }
\end{aligned}
$$

Therefore, the closed-form solution for the price index is

$$
\begin{aligned}
P & =\frac{1}{\rho}\left(\frac{k \varphi_{m}^{k}}{k-\theta+1}\right)^{-\frac{1}{k}}\left(\frac{Y}{\theta}\right)^{\frac{\theta-1-k}{k(\theta-1)}}\left[\begin{array}{c}
\int_{1}^{\lambda_{H}}\left[\lambda^{\frac{r(\theta-1-k)}{\theta-1}}+f_{x} \lambda_{H}^{\frac{-r k}{\theta-1}}\right] \lambda^{k(1-\beta)} d \lambda \\
+\left(1+\tau^{1-\theta}\right)^{\frac{-k}{1-\theta}} \int_{\lambda_{H}}^{\lambda}\left[\lambda^{r}+f_{x}\right]^{\frac{\theta-1-k}{\theta-1}} \lambda^{k(1-\beta)} d \lambda
\end{array}\right]^{-\frac{1}{k}} \\
& =\frac{1}{\rho}\left(\frac{k \varphi_{m}^{k}}{k-\theta+1}\right)^{-\frac{1}{k}}\left(\frac{Y}{\theta}\right)^{\frac{\theta-1-k}{k(\theta-1)}} T(\tau)^{-\frac{1}{k}}
\end{aligned}
$$


where

$$
\begin{aligned}
T(\tau) & =\int_{1}^{\lambda_{H}}\left[\lambda^{\frac{r(\theta-1-k)}{\theta-1}}+f_{x} \lambda_{H}^{\frac{-r k}{\theta-1}}\right] \lambda^{k(1-\beta)} d \lambda \\
& +\left(1+\tau^{1-\theta}\right)^{\frac{k}{\theta-1}} \int_{\lambda_{H}}^{\bar{\lambda}}\left[\lambda^{r}+f_{x}\right]^{\frac{\theta-1-k}{\theta-1}} \lambda^{k(1-\beta)} d \lambda .
\end{aligned}
$$

Lemma 8 The price index $P(\tau)$ is an increasing function of the trade cost $\tau$.

Proof. The task to prove that $P$ is increasing in $\tau$ is equivalent to proving that $T(\tau)$ is decreasing in $\tau$. This derivative is

$$
\begin{aligned}
\frac{d}{d \tau} T(\tau) & =\frac{d}{d \tau} \int_{1}^{\lambda_{H}}\left[\lambda^{\frac{r(\theta-1-k)}{\theta-1}}+f_{x} \lambda_{H}^{\frac{-r k}{\theta-1}}\right] \lambda^{k(1-\beta)} d \lambda \\
& +\frac{d}{d \tau}\left(1+\tau^{1-\theta}\right)^{\frac{-k}{1-\theta}} \int_{\lambda_{H}}^{\bar{\lambda}}\left[\lambda^{r}+f_{x}\right]^{\frac{\theta-1-k}{\theta-1}} \lambda^{k(1-\beta)} d \lambda
\end{aligned}
$$

where it is noted that $\tau$ appears through $\lambda_{H}$ given by (29). Note that the derivatives with respect to $\tau$ of all the lower bounds and upper bounds of the two integrals in $T(\tau)$ sum up to zero as now shown by

$$
\begin{aligned}
& {\left[\lambda_{H}^{\frac{r(\theta-1-k)}{\theta-1}}+f_{x} \lambda_{H}^{\frac{-r k}{\theta-1}}\right] \lambda_{H}^{k(1-\beta)} \frac{d \lambda_{H}}{d \tau}-\left(1+\tau^{1-\theta}\right)^{\frac{-k}{1-\theta}}\left[\lambda_{H}^{r}+f_{x}\right]^{\frac{\theta-1-k}{\theta-1}} \lambda_{H}^{k(1-\beta)} \frac{d \lambda_{H}}{d \tau}} \\
& =\left[\lambda_{H}^{\frac{-r k}{\theta-1}}-\left(1+\tau^{1-\theta}\right)^{\frac{-k}{1-\theta}}\left[\lambda_{H}^{r}+f_{x}\right]^{\frac{-k}{\theta-1}}\right]\left(\lambda_{H}^{r}+f_{x}\right) \lambda_{H}^{k(1-\beta)} \frac{d \lambda_{H}}{d \tau} \\
& =\left[\lambda_{H}^{\frac{-r k}{\theta-1}}-\left(1+\tau^{1-\theta}\right)^{\frac{-k}{1-\theta}}\left[\lambda_{H}^{r}+\frac{\lambda_{H}^{r}}{\tau^{\theta-1}}\right]^{\frac{-k}{\theta-1}}\right]\left(\lambda_{H}^{r}+f_{x}\right) \lambda_{H}^{k(1-\beta)} \frac{d \lambda_{H}}{d \tau} \\
& =0 .
\end{aligned}
$$


Accordingly, by the Leibniz integral rule

$$
\begin{aligned}
\frac{d}{d \tau} T(\tau) & =\int_{1}^{\lambda_{H}} \frac{d}{d \tau}\left[\lambda^{\frac{r(\theta-1-k)}{\theta-1}}+f_{x} \lambda_{H}^{\frac{-r k}{\theta-1}}\right] \lambda^{k(1-\beta)} d \lambda \\
& +\int_{\lambda_{H}}^{\bar{\lambda}} \frac{d}{d \tau}\left(1+\tau^{1-\theta}\right)^{\frac{-k}{1-\theta}}\left[\lambda^{r}+f_{x}\right]^{\frac{\theta-1-k}{\theta-1}} \lambda^{k(1-\beta)} d \lambda \\
& =\int_{1}^{\lambda_{H}} \lambda^{k(1-\beta)} f_{x} \frac{d}{d \tau} \lambda_{H}^{\frac{-r k}{\theta-1}} d \lambda \\
& +\int_{\lambda_{H}}^{\bar{\lambda}}\left[\lambda^{r}+f_{x}\right]^{\frac{\theta-1-k}{\theta-1}} \lambda^{k(1-\beta)} \frac{-k}{1-\theta}\left(1+\tau^{1-\theta}\right)^{\frac{-k}{1-\theta}-1}(1-\theta) \tau^{-\theta} d \lambda \\
& =\int_{1}^{\lambda_{H}} \lambda^{k(1-\beta)} f_{x} \frac{d}{d \tau}\left(\tau^{\theta-1} f_{x}\right)^{\frac{-k}{\theta-1}} d \lambda \\
& -k\left(1+\tau^{1-\theta}\right)^{\frac{\theta-1-k}{1-\theta}} \tau^{-\theta} \int_{\lambda_{H}}^{\bar{\lambda}}\left[\lambda^{r}+f_{x}\right]^{\frac{\theta-1-k}{\theta-1}} \lambda^{k(1-\beta)} d \lambda \\
& =-k \tau^{-k-1} \int_{1}^{\lambda_{H}} \lambda^{k(1-\beta)} f_{x}^{\frac{\theta-1-k}{\theta-1}} d \lambda \\
& -k\left(1+\tau^{1-\theta}\right)^{\frac{\theta-1-k}{1-\theta}} \tau^{-\theta} \int_{\lambda_{H}}^{\bar{\lambda}}\left[\lambda^{r}+f_{x}\right]^{\frac{\theta-1-k}{\theta-1}} \lambda^{k(1-\beta)} d \lambda \\
& <0 .
\end{aligned}
$$

This completes the proof that $T(\tau)$ is decreasing in $\tau$ and thus that $P(\tau)$ is increasing in $\tau$. 


\section{A.2 Propositions and Corollaries}

Proof. (Proposition 1) Lemma 2 indicates that $\varphi^{D}(\lambda)=\varphi^{d}(\lambda)$ for $\lambda<\lambda_{H}$ while Lemma 3 indicates that $\varphi^{d}(\lambda)$ is increasing in $\lambda$, so $\varphi^{D}(\lambda)$ is increasing in $\lambda$ for $\lambda<\lambda_{H}$. Also, Lemma 2 states that $\varphi^{X}(\lambda)=\varphi^{L}(\lambda)$ for $\lambda<\lambda_{H}$ while Lemma 4 states that $\varphi^{L}(\lambda)$ is decreasing in $\lambda$, so $\varphi^{X}(\lambda)$ is decreasing in $\lambda$ for $\lambda<\lambda_{H}$.

Proof. (Proposition 2) Lemma 3 has proved that $\varphi^{d}(\lambda)$ is increasing in $\lambda$ for all $\lambda$, Lemma 2 states that $\varphi^{X}(\lambda)=\varphi^{H}(\lambda)$ for $\lambda>\lambda_{H}$ and Lemma 1 shows that $\varphi^{d}(\lambda)>$ $\varphi^{H}(\lambda)$ for $\lambda>\lambda_{H}$. Accordingly, it follows that $\varphi^{d}(\lambda)>\varphi^{X}(\lambda)$ for $\lambda>\lambda_{H}$.

\section{Proof. (Proposition 3)}

(a) From Lemmas 5 and $6, \varphi^{H}(\lambda)$ is decreasing in $\lambda$ for all $\lambda<\lambda_{M}$ and so $\varphi^{H}(\lambda)$ is decreasing in $\lambda$ for $\lambda_{H}<\lambda<\lambda_{M}$.

(b) From Lemma 5 and $6, \varphi^{H}(\lambda)$ is increasing in $\lambda$ for all $\lambda>\lambda_{M}$ and so $\varphi^{H}(\lambda)$ is increasing in $\lambda$ for all $\lambda>\lambda_{M}>\lambda_{H}$.

Proof. (Corollary 1) The derivative of expression (22) for the highest quality that a firm will produce and sell domestically, $\lambda^{d}(\varphi)$, is

$$
\frac{\partial \lambda^{d}(\varphi)}{\partial \varphi}=\frac{\theta-1}{r-\gamma} \varphi^{\frac{\theta-1}{r-\gamma}-1} \kappa^{\frac{1}{r-\gamma}}>0
$$

where the positive sign arises because $r-\gamma>0$ and $\theta-1>0$ by assumption. Hence, $\lambda^{d}(\varphi)$ is increasing in $\varphi$ so the quality range is increasing in $\lambda$.

Proof. (Corollary 2) We need to prove that the minimum productivity cutoff to export is $\varphi^{H}$, given by (30), if $\lambda_{M}<\lambda_{H}$ and $\varphi^{M}$ if $\lambda_{M}>\lambda_{H}$, where

$$
\varphi^{M} \equiv \varphi^{H}\left(\lambda_{M}\right)=\left(\frac{f_{x}}{r-\gamma}\right)^{\frac{r-\gamma}{r(\theta-1)}}\left[\frac{\kappa}{r}\left(1+\tau^{1-\theta}\right)\right]^{\frac{1}{1-\theta}} \gamma^{\frac{\beta-1}{r}} .
$$

(i) From Proposition 1, the productivity cutoff to export $\varphi^{X}(\lambda)$ is decreasing in $\lambda$ for $\lambda \leqslant \lambda_{H}$ and so the minimum of $\varphi^{X}(\lambda)$ over $\left[1, \lambda_{H}\right]$ is $\varphi^{X}\left(\lambda_{H}\right)=\varphi^{H}$. Now considering the remaining quality range $\left[\lambda_{H}, \bar{\lambda}\right]$, it is noted from Lemma 2 that the productivity cutoff to export, $\varphi^{X}(\lambda)$, is $\varphi^{H}(\lambda)$ for $\lambda \geqslant \lambda_{H}$. First, consider the case when $\lambda_{M}<\lambda_{H}$. (ii) Lemmas 5 and 6 imply that $\varphi^{H}(\lambda)$ is increasing in $\lambda$ for all $\lambda \geqslant \lambda_{H}>\lambda_{M}$, so the minimum of $\varphi^{X}(\lambda)$ over $\left[\lambda_{H}, \lambda\right]$ is $\varphi^{H}\left(\lambda_{H}\right)=\varphi^{H}$. Second, consider the case when $\lambda_{M}>\lambda_{H}$. (iii) Lemmas 5 and 6 imply that $\varphi^{H}(\lambda)$ has a unique minimum at $\lambda=\lambda_{M}$, so the minimum of $\varphi^{H}(\lambda)$ over $\left[\lambda_{H}, \bar{\lambda}\right]$ is $\varphi^{H}\left(\lambda_{M}\right)=\varphi^{M}$. Since $\varphi^{X}(\lambda)$ is $\varphi^{H}(\lambda)$ for $\lambda \geqslant \lambda_{H}$, the minimum of $\varphi^{X}(\lambda)$ over $\left[\lambda_{H}, \bar{\lambda}\right]$ is $\varphi^{M}$. Note that if $\lambda_{M}>\lambda_{H}$ then $\varphi^{H}>\varphi^{M}$. This is because Lemmas 5 and 6 imply that $\varphi^{H}(\lambda)$ is decreasing in $\lambda$ for all $\lambda_{H} \leqslant \lambda<\lambda_{M}$ 
and so $\varphi^{H}\left(\lambda_{H}\right)>\varphi^{H}\left(\lambda_{M}\right)$, i.e., $\varphi^{H}>\varphi^{M}$. Thus, results (i), (ii) and (iii) imply that the minimum of $\varphi^{X}(\lambda)$ is $\varphi^{H}$ for all $\lambda \in[1, \bar{\lambda}]$ if $\lambda_{M}<\lambda_{H}$ and the minimum of $\varphi^{X}(\lambda)$ is $\varphi^{M}$ for all $\lambda \in[1, \lambda]$ if $\lambda_{M}>\lambda_{H}$.

Proof. (Corollary 3) Using the productivity cutoff to export a low quality variety, given by expression (25), we can derive the export variety quality cutoff for a firm, i.e., the lower bound of the export product quality range as

$$
\lambda_{\min }^{X}(\varphi)=\varphi^{-\frac{1}{1-\beta}}\left[\tau^{\theta-1} \frac{f_{x}}{\kappa}\right]^{\frac{1}{\gamma}}
$$

Its derivative is

$$
\frac{\partial \lambda_{\min }^{X}(\varphi)}{\partial \varphi}=-\frac{1}{1-\beta} \varphi^{-\frac{1}{1-\beta}-1}\left[\tau^{\theta-1} \frac{f_{x}}{\kappa}\right]^{\frac{1}{\gamma}}<0
$$

since $1-\beta>0$ by assumption. Therefore, the lower bound of the export product quality range decreases in productivity. It follows that the export product quality range expands to the lower end as a firm's productivity increases. This also means the low-end quality range that is only sold domestically, which is bounded by $\lambda_{\min }^{X}(\varphi)$, decreases as productivity increases. Using expression (26) for the productivity cutoff yielding zero export profit, we can derive the highest variety quality level that a firm can export, i.e., the upper bound of the export product quality range, $\lambda_{\max }^{X}(\varphi)$, but a closed-form solution to this upper bound is not available. Since the export productivity cutoff function $\varphi^{H}(\lambda)$, given by (26),

$$
\varphi^{H}(\lambda)=\left[\frac{\lambda^{r}+f_{x}}{\kappa\left(1+\tau^{1-\theta}\right)}\right]^{\frac{1}{\theta-1}} \lambda^{\beta-1}
$$

is a continuous function and strictly increasing in $\lambda$ for $\lambda>\lambda_{M}$, it has an one-to-one property and the upper bound of the export quality range $\lambda_{\max }^{X}(\varphi)$ is its inverse function

$$
\lambda_{\max }^{X}(\varphi)=\left[\varphi^{H}(\lambda)\right]^{-1}
$$

Using the inverse function theorem, we have

$$
\frac{\partial \lambda_{\max }^{X}(\varphi)}{\partial \varphi}=\left(\left[\varphi^{H}(\lambda)\right]^{-1}\right)^{\prime}=\left[\frac{\partial \varphi^{H}(\lambda)}{\partial \varphi}\right]^{-1}>0
$$

for $\lambda>\lambda_{M}$. Therefore, the upper bound of the export product quality range, $\lambda_{\max }^{X}(\varphi)$, is increasing in $\lambda$ for $\lambda>\lambda_{M}$. This implies that the export productivity quality range, 
bounded by $\left[\lambda_{\min }^{X}(\varphi), \lambda_{\max }^{X}(\varphi)\right]$, expands toward both the lower and higher ends as productivity increases.

Proof. (Corollary 4) To prove this proposition, we need to show that for firms that have the export option (i.e., firms with productivity levels equal or greater than the minimum productivity to export), there is a range of variety quality $\lambda$ such that $\pi^{d}(\lambda, \varphi)<0$ and $\pi^{d+x}(\lambda, \varphi)>0$.

On the one hand, from the profit rule (24) it is known that $\pi^{d}(\lambda, \varphi)<0$ for $\lambda>\lambda^{d}(\varphi)$. On the other hand, given the definition of the export quality upper bound in the proof of proposition 3 as

$$
\lambda_{\max }^{X}(\varphi)=\left[\varphi^{H}(\lambda)\right]^{-1}
$$

it follows that

$$
\varphi=\varphi^{H}\left(\lambda_{\max }^{X}(\varphi)\right) .
$$

Since $\varphi^{H}(\lambda)$ is increasing in $\lambda$ for $\lambda>\lambda_{M}$, we have $\varphi=\varphi^{H}\left(\lambda_{\max }^{X}(\varphi)\right)>\varphi^{H}(\lambda)$ for $\lambda_{\max }^{X}(\varphi)>\lambda>\lambda_{M}$. It follows from the profit rule $(24)$ that $\pi^{d+x}(\lambda, \varphi)>0$. Together, these establish that $\pi^{d}(\lambda, \varphi)<0$ for $\lambda>\lambda^{d}(\varphi)$ and $\pi^{d+x}(\lambda, \varphi)>0$ for $\lambda_{M}<\lambda<\lambda_{\max }^{X}(\varphi)$. (result a)

The next task is to prove that $\lambda^{d}(\varphi)<\lambda_{\max }^{X}(\varphi)$ for those firms with the option to export. Since it can be shown that

$$
\frac{\varphi^{H}(\lambda)}{\varphi^{d}(\lambda)}=\left(\frac{1+\lambda^{-r} f_{x}}{1+\tau^{1-\theta}}\right)^{\frac{1}{\theta-1}}=\left(\frac{1+\lambda^{-r} f_{x}}{1+\lambda_{H}^{-r} f_{x}}\right)^{\frac{1}{\theta-1}},
$$

it follows that

$$
\frac{\varphi^{H}(\lambda)}{\varphi^{d}(\lambda)}<1 \text { or } \varphi^{d}(\lambda)>\varphi^{H}(\lambda) \text { for } \lambda>\lambda_{H}
$$

and

$$
\frac{\varphi^{H}(\lambda)}{\varphi^{d}(\lambda)}>1 \text { or } \varphi^{d}(\lambda)<\varphi^{H}(\lambda) \text { for } \lambda<\lambda_{H} .
$$


Since

$$
\varphi^{H}\left(\lambda_{\max }^{X}(\varphi)\right)=\varphi^{d}\left(\lambda^{d}(\varphi)\right)=\varphi
$$

it follows that $\lambda_{\max }^{X}(\varphi)>\lambda^{d}(\varphi)$ if $\lambda_{\max }^{X}(\varphi)>\lambda^{d}(\varphi)>\lambda_{H} \cdot($ result b)

Since $\lambda^{d}(\varphi)$, given by expression $(22)$, is increasing in $\varphi$ (see Proposition 1 and its proof), then $\lambda^{d}(\varphi)>\lambda^{d}\left(\varphi^{H}\right)=\lambda_{H}$ for $\varphi>\varphi^{H}$. (result c)

If $\lambda_{H}>\lambda_{M}$ (using results (a)-(c)), for all firms that can export, i.e., for $\varphi>\varphi^{H}$, there exists a range of high quality levels $\lambda_{\max }^{X}(\varphi)>\lambda>\lambda^{d}(\varphi)>\lambda_{H}$ such that $\pi^{d}(\lambda, \varphi)<0$ and $\pi^{d+x}(\lambda, \varphi)>0$, which is now proved. If $\lambda_{H}<\lambda_{M}$, the minimum productivity to export is $\varphi^{M}<\varphi^{H}$ (see Proposition 2 and its proof). (i) For all highly productive exporters, i.e., $\varphi>\varphi^{H}$, following results (a), (b) and (c), the range of quality that is only profitable in the export market is specified as above. (ii) For less productive exporters, i.e., firms in the productivity range $\varphi^{M}<\varphi<\varphi^{H}$, then $\lambda^{d}(\varphi)<\lambda^{d}\left(\varphi^{H}\right)=\lambda_{H}<\lambda_{M}$. (result d)

In addition, there exists a range of quality that is non profitable in the domestic market but profitable through exporting for these firms. The specification of this quality range is, however, slightly different from the one described above. Because $\varphi^{H}(\lambda)$ is decreasing in $\lambda$ for $\lambda<\lambda_{M}$ and $\varphi^{H}(\lambda)$ is increasing in $\lambda$ for $\lambda>\lambda_{M}$, there are two solutions to $\lambda_{\max }^{X}(\varphi)$ in the equation

$$
\varphi=\varphi^{H}\left(\lambda_{\max }^{X}(\varphi)\right)
$$

where $\varphi=\varphi^{H}\left(\lambda_{\max }^{X}(\varphi)\right)>\varphi^{H}(\lambda)$ for $\lambda_{\max }^{X}(\varphi)>\lambda>\lambda_{M}$ and $\varphi=\varphi^{H}\left(\lambda_{\max }^{X}(\varphi)\right)>$ $\varphi^{H}(\lambda)$ for $\lambda_{\max }^{X \prime}(\varphi)<\lambda<\lambda_{M}$. Hence, for the whole range $\lambda_{\max }^{X \prime}(\varphi)<\lambda<\lambda_{\max }^{X}(\varphi)$, we have $\varphi>\varphi^{H}(\lambda)$ and thus $\pi^{d+x}(\lambda, \varphi)>0$. (result e)

Finally, because $\varphi^{H}(\lambda)$ is decreasing in $\lambda$ for $\lambda_{H}<\lambda<\lambda_{M}$, its inverse function $\lambda_{\max }^{X \prime}(\varphi)=\left[\varphi^{H}(\lambda)\right]^{-1}$ is decreasing over the range $\varphi<\varphi^{H}$, so $\lambda_{\max }^{X \prime}(\varphi)>\lambda_{\max }^{X \prime}\left(\varphi^{H}\right)=$ $\lambda_{H} \cdot($ result f)

Results (a), (d), (e) and (f) imply that $\lambda^{d}(\varphi)<\lambda_{H}<\lambda_{\max }^{X \prime}(\varphi)<\lambda<\lambda_{\max }^{X}(\varphi)$. Thus, for the quality range $\lambda^{d}(\varphi)<\lambda_{\max }^{X \prime}(\varphi)<\lambda<\lambda_{\max }^{X}(\varphi)$, we have $\pi^{d}(\lambda, \varphi)<0$ and $\pi^{d+x}(\lambda, \varphi)>0$, which was to be shown.

Proposition 7 (a) A higher quality variety generates higher domestic and export revenues for the firm, i.e., both domestic and export revenue are increasing in $\lambda, \forall \lambda>0$. 
(b) The domestic and export supplies, $q^{d}(\lambda, \varphi)$ and $q^{x}(\lambda, \varphi)$, are increasing in $\lambda$ for low values of $\beta$, and decreasing in $\lambda$ for sufficiently high values of $\beta$.

Proof. (Proposition 7) (a) Using expressions (10) and (11) for $p^{d}$ and $q^{d}$, domestic revenue may be expressed as $R^{d}(\lambda, \varphi)=Y(\varphi \rho P)^{\theta-1} \lambda^{\gamma}$. Since $\gamma>0$, it follows that domestic revenue is increasing in quality $\lambda$. Using (15) and (16), repeated as $p^{x}(\lambda, \varphi)=\tau p^{d}(\lambda, \varphi)$ and $q^{x}(\lambda, \varphi)=\tau^{-\theta} q^{d}(\lambda, \varphi)$, it is readily shown that export revenue is a multiple of domestic revenue, $R^{x}(\lambda, \varphi)=\tau^{1-\theta} R^{d}(\lambda, \varphi)$. Accordingly, export revenue is also increasing in $\lambda$. (b) Using expression (11) for $q^{d}$, repeated as $q^{d}(\lambda, \varphi)=Y P^{\theta-1}(\varphi \rho)^{\theta} \lambda^{\theta(1-\beta)-1}$, it follows that

$$
\frac{d}{d \lambda} q^{d}(\lambda, \varphi)>0 \Longleftrightarrow \theta(1-\beta)-1>0 \Longleftrightarrow \beta<\frac{\theta-1}{\theta}=\rho .
$$

Accordingly,

$$
\frac{d}{d \lambda} q^{d}(\lambda, \varphi)\left\{\begin{array}{ll}
>0 & \text { for } \beta<\rho \\
<0 & \text { for } \beta>\rho
\end{array} .\right.
$$

Since export quantities are related to domestic quantities by $q^{x}(\lambda, \varphi)=\tau^{-\theta} q^{d}(\lambda, \varphi)$, the same qualitative results apply for export quantities as for domestic quantities.

Proof. (Proposition 4) (a) Using the expression for $\varphi^{d}(\lambda)$ in (20) and noting the dependence on $\tau$ through $P(\tau)$ in $\kappa=\frac{Y}{\theta}(\rho P)^{\theta-1}$, we have

$$
\begin{aligned}
\frac{d}{d \tau} \varphi^{d}(\lambda) & =\frac{d}{d \tau}\left[\lambda^{\frac{r-\gamma}{\theta-1}} \kappa^{\frac{1}{1-\theta}}\right] \\
& =\frac{d}{d \tau}\left[\lambda^{\frac{r-\gamma}{\theta-1}}\left(\frac{Y}{\theta}\right)^{\frac{1}{1-\theta}}(\rho P)^{-1}\right] \\
& =-\lambda^{\frac{r-\gamma}{\theta-1}}\left(\frac{Y}{\theta}\right)^{\frac{1}{1-\theta}} \rho^{-1} \frac{1}{P^{2}} \frac{d P}{d \tau} \\
& <0
\end{aligned}
$$

where the sign follows from the result that $\frac{d P}{d \tau}>0$ in Lemma 8 .

To prove part (b) of the proposition, we next prove that $\frac{d}{d \tau} \varphi^{X}(\lambda)>0$ for $\forall \lambda$, where $\varphi^{X}(\lambda)$ is given by (33). Hence, we need to show that (i) $\frac{d}{d \tau} \varphi^{L}(\lambda)>0$ for all $\forall \lambda<\lambda_{H}$ and (ii) $\frac{d}{d \tau} \varphi^{H}(\lambda)>0$ for all $\forall \lambda \geqslant \lambda_{H}$. 
(i) Using the expression of $\varphi^{L}(\lambda)$ in (25) and solution for $P$ in Lemma 7, we have

$$
\begin{aligned}
\frac{d}{d \tau} \varphi^{L}(\lambda) & =\frac{d}{d \tau}\left[\tau \lambda^{\beta-1} f_{x}^{\frac{1}{1-\theta}}\left(\frac{Y}{\theta}\right)^{\frac{1}{1-\theta}}(\rho P)^{-1}\right] \\
& =\lambda^{\beta-1} f_{x}^{\frac{1}{1-\theta}}\left(\frac{Y}{\theta}\right)^{\frac{1}{1-\theta}} \rho^{-1} \frac{d}{d \tau}\left(\tau P^{-1}\right) \\
& =\lambda^{\beta-1} f_{x}^{\frac{1}{1-\theta}}\left(\frac{Y}{\theta}\right)^{\frac{1}{1-\theta}} \rho^{-1} \frac{d}{d \tau}\left[\tau \rho\left(\frac{k \varphi_{m}^{k}}{k-\theta+1}\right)^{\frac{1}{k}}\left(\frac{Y}{\theta}\right)^{-\frac{\theta-1-k}{k(\theta-1)}} T(\tau)^{\frac{1}{k}}\right] \\
& =\lambda^{\beta-1} f_{x}^{\frac{1}{1-\theta}}\left(\frac{Y}{\theta}\right)^{-\frac{1}{k}}\left(\frac{k \varphi_{m}^{k}}{k-\theta+1}\right)^{\frac{1}{k}} \frac{d}{d \tau}\left[\tau T(\tau)^{\frac{1}{k}}\right] .
\end{aligned}
$$

We will show below that $\frac{d}{d \tau}\left[\tau T(\tau)^{\frac{1}{k}}\right]>0$ or, equivalently, that $\frac{d}{d \tau}\left[\tau^{k} T(\tau)\right]>0$.

$$
\begin{aligned}
\frac{d}{d \tau}\left[\tau^{k} T(\tau)\right] & =\frac{d}{d \tau} \int_{1}^{\lambda_{H}} \tau^{k}\left[\lambda^{\frac{r(\theta-1-k)}{\theta-1}}+f_{x} \lambda_{H}^{\frac{-r k}{\theta-1}}\right] \lambda^{k(1-\beta)} d \lambda \\
& +\frac{d}{d \tau} \tau^{k}\left(1+\tau^{1-\theta}\right)^{\frac{-k}{1-\theta}} \int_{\lambda_{H}}^{\bar{\lambda}}\left[\lambda^{r}+f_{x}\right]^{\frac{\theta-1-k}{\theta-1}} \lambda^{k(1-\beta)} d \lambda \\
& =\frac{d}{d \tau} \int_{1}^{\lambda_{H}}\left[\tau^{k} \lambda^{\frac{r(\theta-1-k)}{\theta-1}}+f_{x}^{\frac{\theta-1-k}{\theta-1}}\right] \lambda^{k(1-\beta)} d \lambda \\
& +\frac{d}{d \tau}\left(\tau^{\theta-1}+1\right)^{\frac{k}{\theta-1}} \int_{\lambda_{H}}^{\bar{\lambda}}\left[\lambda^{r}+f_{x}\right]^{\frac{\theta-1-k}{\theta-1}} \lambda^{k(1-\beta)} d \lambda .
\end{aligned}
$$

It can be shown, similarly to the proof of Lemma 8, that the derivatives of all the lower bounds and upper bounds of the two integrals sum up to zero and so, by the Leibniz rule, we have that

$$
\begin{aligned}
\frac{d}{d \tau}\left[\tau^{k} T(\tau)\right] & =\int_{1}^{\lambda_{H}} \lambda^{k(1-\beta)} \frac{d}{d \tau}\left[\tau^{k} \lambda^{\frac{r(\theta-1-k)}{\theta-1}}+f_{x}^{\frac{\theta-1-k}{\theta-1}}\right] d \lambda \\
& +\int_{\lambda_{H}}^{\bar{\lambda}} \lambda^{k(1-\beta)}\left[\lambda^{r}+f_{x}\right]^{\frac{\theta-1-k}{\theta-1}} \frac{d}{d \tau}\left(\tau^{\theta-1}+1\right)^{\frac{k}{\theta-1}} d \lambda \\
& =\int_{1}^{\lambda_{H}} \lambda^{k(1-\beta)} \lambda^{\frac{r(\theta-1-k)}{\theta-1}} k \tau^{k-1} d \lambda \\
& +\int_{\lambda_{H}}^{\bar{\lambda}} \lambda^{k(1-\beta)}\left[\lambda^{r}+f_{x}\right]^{\frac{\theta-1-k}{\theta-1}} k\left(\tau^{\theta-1}+1\right)^{\frac{k}{\theta-1}-1} \tau^{\theta-2} d \lambda \\
& >0
\end{aligned}
$$

which was to be shown. 
(ii) Using the expression of $\varphi^{H}(\lambda)$ in (26) and solution for $P$ in Lemma 7 , we have

$$
\begin{aligned}
\frac{d}{d \tau} \varphi^{H}(\lambda) & =\frac{d}{d \tau}\left[\left(\lambda^{r}+f_{x}\right)^{\frac{1}{\theta-1}} \lambda^{\beta-1}\left(\frac{Y}{\theta}\right)^{\frac{1}{1-\theta}}\left(1+\tau^{1-\theta}\right)^{\frac{1}{1-\theta}}(\rho P)^{-1}\right] \\
& =\left(\lambda^{r}+f_{x}\right)^{\frac{1}{\theta-1}} \lambda^{\beta-1}\left(\frac{Y}{\theta}\right)^{\frac{1}{1-\theta}} \rho^{-1} \frac{d}{d \tau}\left[\left(1+\tau^{1-\theta}\right)^{\frac{1}{1-\theta}} P^{-1}\right] \\
& =\left(\lambda^{r}+f_{x}\right)^{\frac{1}{\theta-1}} \lambda^{\beta-1}\left(\frac{Y}{\theta}\right)^{\frac{1}{1-\theta}} \rho^{-1} \frac{d}{d \tau}\left[\left(1+\tau^{1-\theta}\right)^{\frac{1}{1-\theta}} \rho\left(\frac{k \varphi_{m}^{k}}{k-\theta+1}\right)^{\frac{1}{k}}\left(\frac{Y}{\theta}\right)^{-\frac{\theta-1-k}{k(\theta-1)}} T(\tau)^{\frac{1}{k}}\right] \\
& =\left(\lambda^{r}+f_{x}\right)^{\frac{1}{\theta-1}} \lambda^{\beta-1}\left(\frac{Y}{\theta}\right)^{-\frac{1}{k}}\left(\frac{k \varphi_{m}^{k}}{k-\theta+1}\right)^{\frac{1}{k}} \frac{d}{d \tau}\left[\left(1+\tau^{1-\theta}\right)^{\frac{1}{1-\theta}} T(\tau)^{\frac{1}{k}}\right] .
\end{aligned}
$$

We now show below that $\frac{d}{d \tau}\left[\left(1+\tau^{1-\theta}\right)^{\frac{1}{1-\theta}} T(\tau)^{\frac{1}{k}}\right]>0$ or, equivalently, that $\frac{d}{d \tau}\left[\left(1+\tau^{1-\theta}\right)^{\frac{k}{1-\theta}} T(\tau)\right]>$ 0 . This derivative is

$$
\begin{aligned}
\frac{d}{d \tau}\left[\left(1+\tau^{1-\theta}\right)^{\frac{k}{1-\theta}} T(\tau)\right] & =\frac{d}{d \tau} \int_{1}^{\lambda_{H}}\left(1+\tau^{1-\theta}\right)^{\frac{k}{1-\theta}}\left[\lambda^{\frac{r(\theta-1-k)}{\theta-1}}+f_{x} \lambda_{H}^{\frac{-r k}{\theta-1}}\right] \lambda^{k(1-\beta)} d \lambda \\
& +\frac{d}{d \tau} \int_{\lambda_{H}}^{\bar{\lambda}}\left[\lambda^{r}+f_{x}\right]^{\frac{\theta-1-k}{\theta-1}} \lambda^{k(1-\beta)} d \lambda .
\end{aligned}
$$

Since the derivatives of all the lower bounds and upper bounds of the two integrals sum up to zero, the Leibniz rule yields

$$
\begin{aligned}
& \frac{d}{d \tau}\left[\left(1+\tau^{1-\theta}\right)^{\frac{k}{1-\theta}} T(\tau)\right] \\
& =\int_{1}^{\lambda_{H}} \frac{d}{d \tau}\left(1+\tau^{1-\theta}\right)^{\frac{k}{1-\theta}}\left[\lambda^{\frac{r(\theta-1-k)}{\theta-1}}+\tau^{-k} f_{x}^{\frac{\theta-1-k}{\theta-1}}\right] \lambda^{k(1-\beta)} d \lambda \\
& +\int_{\lambda_{H}}^{\bar{\lambda}} \frac{d}{d \tau}\left[\lambda^{r}+f_{x}\right]^{\frac{\theta-1-k}{\theta-1}} \lambda^{k(1-\beta)} d \lambda \\
& =\int_{1}^{\lambda_{H}}\left[\frac{d}{d \tau}\left(1+\tau^{1-\theta}\right)^{\frac{k}{1-\theta}} \lambda^{\frac{r(\theta-1-k)}{\theta-1}}+\frac{d}{d \tau}\left(\tau^{\theta-1}+1\right)^{\frac{k}{1-\theta}} f_{x}^{\frac{\theta-1-k}{\theta-1}}\right] \lambda^{k(1-\beta)} d \lambda \\
& =\int_{1}^{\lambda_{H}}\left[k\left(1+\tau^{1-\theta}\right)^{\frac{k}{1-\theta}-1} \tau^{-\theta} \lambda^{\frac{r(\theta-1-k)}{\theta-1}}-k\left(\tau^{\theta-1}+1\right)^{\frac{k}{1-\theta}-1} \tau^{\theta-2} f_{x}^{\frac{\theta-1-k}{\theta-1}}\right] \lambda^{k(1-\beta)} d \lambda \\
& =\int_{1}^{\lambda_{H}}\left[\lambda^{\frac{r(\theta-1-k)}{\theta-1}}-\tau^{\theta-k-1} f_{x}^{\frac{\theta-1-k}{\theta-1}}\right] \tau^{-\theta} k\left(1+\tau^{1-\theta}\right)^{\frac{k}{1-\theta}-1} \lambda^{k(1-\beta)} d \lambda \\
& =\int_{1}^{\lambda_{H}}\left[\lambda^{\frac{r(\theta-1-k)}{\theta-1}}-\lambda_{H}^{\frac{r(\theta-1-k)}{\theta-1}}\right] \tau^{-\theta} k\left(1+\tau^{1-\theta}\right)^{\frac{k}{1-\theta}-1} \lambda^{k(1-\beta)} d \lambda
\end{aligned}
$$

$>0$. 
The sign follows because the term in square brackets $\left[\lambda^{\frac{r(\theta-1-k)}{\theta-1}}-\lambda_{H}^{\frac{r(\theta-1-k)}{\theta-1}}\right]>0$ for $\lambda \in\left[1, \lambda_{H}\right]$, since $\frac{r(\theta-1-k)}{\theta-1}<0$ by assumption. Therefore, this proves (ii). Results in (i) and (ii) prove the required result for part (b) of the proposition.

Proof. (Proposition 5) We need to prove that under a reduction in the trade cost $\tau$ : (a) the share of low-end exporters increases, (b) for firms that serve the domestic market only, $\varphi<\varphi_{H}$, their quality ranges shrink toward the lower end of the quality ladder, (c) the export quality range of the incumbent exporters expands toward both the lower end and the higher end of the quality ladder, (d) for new exporters which are less productive, their quality ranges shrink toward the lower end of the quality ladder, (e) for new exporter which are more productive, their quality ranges expand toward the upper end of the quality ladder.

(a) Given the expression of $\kappa=\frac{Y}{\theta}(\rho P)^{\theta-1}$, its derivative is

$$
\frac{d}{d \tau} \kappa=\frac{Y}{\theta} \rho^{\theta-1}(\theta-1) P^{\theta-2} \frac{d}{d \tau} P>0
$$

because $\frac{d}{d \tau} P>0$ following the proof for Lemma 8 . It follows that

$$
\frac{d}{d \tau} \varphi_{H}=f_{x}^{\frac{r-\gamma}{r(\theta-1)}} \frac{d}{d \tau}\left(\kappa^{\frac{1}{1-\theta}} \tau^{\frac{r-\gamma}{r}}\right)>0 \text { at the assumption (21) that } r \geqslant \gamma .
$$

Therefore, after a reduction from $\tau$ to $\tau^{\prime}<\tau$, the productivity cutoff to export a variety decreases from $\varphi_{H}$ to $\varphi_{H}^{\prime}$, allowing for less productive firms with productivity in the range $\varphi_{H}>\varphi>\varphi_{H}^{\prime}$ to start exporting. Since the highest quality that a firm can produce increases in its productivity, these less productive firms export the lower-end varieties. Hence, the share of low-end exporters in the market increases.

(b) Since $\frac{d}{d \tau} \kappa>0$ as shown in (a), it follows that

$$
\frac{d}{d \tau} \lambda^{d}(\varphi)=\varphi^{\frac{\theta-1}{r-\gamma}} \frac{1}{r-\gamma} \kappa^{\frac{1}{r-\gamma}-1} \frac{d}{d \tau} \kappa>0 .
$$

Therefore, the highest quality that a firm without an opportunity to export can produce decreases when there is a reduction in trade cost.

(c) It is required to prove that the lower bound and the upper bound of the export quality range of an exporting firm decrease under a reduction in trade cost, i.e., $\frac{d}{d \tau} \lambda_{\min }^{X}(\varphi)>0$ and $\frac{d}{d \tau} \lambda_{\max }^{X}(\varphi)>0$. Given the expression of the lower bound of the export product 
quality range in the proof for Proposition 4, the expression of $\kappa$ and the solution to $P$ in the proof for Lemma 8, we can rewrite the expression of the lower bound as, using the same function notations but explicitly including $\tau$ as an argument,

$$
\begin{aligned}
\lambda_{\min }^{X}(\varphi, \tau) & =\varphi^{-\frac{1}{1-\beta}}\left[\tau^{\theta-1} \frac{f_{x}}{\kappa}\right]^{\frac{1}{\gamma}} \\
& =\varphi^{-\frac{1}{1-\beta}}\left[\tau^{\theta-1} P^{1-\theta} \frac{\theta f_{x}}{Y \rho^{\theta-1}}\right]^{\frac{1}{\gamma}} \\
& =\varphi^{-\frac{1}{1-\beta}}\left[\tau^{k} T(\tau)\right]^{\frac{\theta-1}{\gamma k}}\left(\frac{\theta}{Y} \frac{k \varphi_{m}^{k}}{k-\theta+1}\right)^{\frac{\theta-1}{\gamma k}} f_{x}^{\frac{1}{\gamma}} .
\end{aligned}
$$

In the proof of Proposition 4, we proved that $\frac{d}{d \tau}\left[\tau^{k} T(\tau)\right]>0$, so $\frac{d}{d \tau} \lambda_{\min }^{X}(\varphi, \tau)>0$ as required to be shown. We do not have a closed-form solution to $\lambda_{\max }^{X}(\varphi, \tau)$ but we can prove that $\frac{d}{d \tau} \lambda_{\max }^{X}(\varphi, \tau)>0$ as below. Note that the export productivity cutoff function $\varphi^{H}(\lambda, \tau)$, given by (28), is a continuous function and strictly increasing in $\tau$ as proved in the proof of Proposition 4. It, hence, has an one-to-one property and its inverse function exists which is the upper bound of the export quality range $\lambda_{\max }^{X}(\varphi, \tau)$

$$
\lambda_{\max }^{X}(\varphi, \tau)=\varphi^{H^{-1}}(\lambda, \tau) .
$$

Using the inverse function theorem, we have

$$
\frac{d}{d \tau} \lambda_{\max }^{X}(\varphi, \tau)=\frac{d}{d \tau} \varphi^{H^{-1}}(\lambda, \tau)=\left[\frac{d}{d \tau} \varphi^{H}(\lambda(\varphi, \tau))\right]^{-1}
$$

Because $\frac{d}{d \tau} \varphi^{H}(\lambda)>0$ as proved in the proof for Lemma $8, \frac{d}{d \tau} \lambda_{\max }^{X}(\varphi, \tau)>0$, which was to be proved. This implies that the export productivity quality range, bounded by $\left[\lambda_{\min }^{X}(\varphi, \tau), \lambda_{\max }^{X}(\varphi, \tau)\right]$, expands toward both the lower end and the higher end as $\tau$ decreases.

(d) and (e). A reduction of trade cost from $\tau$ to $\tau^{\prime}<\tau$ allows firms with productivity in the range $\varphi_{H}>\varphi>\varphi_{H}^{\prime}$ to start exporting. For these new exporters, the highest quality that they can produce under the previous level of trade cost, $\tau$, is $\varphi^{d}(\lambda, \tau)$ while the highest level of quality it can produce and export under the new level of trade cost $\tau^{\prime}$ is $\varphi^{H}\left(\lambda, \tau^{\prime}\right)$. Consider the ratio $\frac{\varphi^{H}\left(\lambda, \tau^{\prime}\right)}{\varphi^{d}(\lambda, \tau)}$, which can be rewritten as follows

$$
\frac{\varphi^{H}\left(\lambda, \tau^{\prime}\right)}{\varphi^{d}(\lambda, \tau)}=\frac{\varphi^{H}\left(\lambda, \tau^{\prime}\right)}{\varphi^{d}\left(\lambda, \tau^{\prime}\right)} \frac{\varphi^{d}\left(\lambda, \tau^{\prime}\right)}{\varphi^{d}(\lambda, \tau)}
$$


Using the expression of $\varphi^{d}(\lambda, \tau), \varphi^{H}\left(\lambda, \tau^{\prime}\right)$ and $\kappa=\frac{Y}{\theta}(\rho P)^{\theta-1}$, the ratio can be rewritten as

$$
\frac{\varphi^{H}\left(\lambda, \tau^{\prime}\right)}{\varphi^{d}(\lambda, \tau)}=\frac{\varphi^{H}\left(\lambda, \tau^{\prime}\right)}{\varphi^{d}\left(\lambda, \tau^{\prime}\right)} \frac{P(\tau)}{P\left(\tau^{\prime}\right)}=\left(\frac{1+\lambda^{-r} f_{x}}{1+\lambda_{H}^{\prime-r} f_{x}}\right)^{\frac{1}{\theta-1}} \frac{P(\tau)}{P\left(\tau^{\prime}\right)}
$$

In expression (A.3), there are two component effects that move in opposite directions, i.e., the trade-induced innovation effect, $\frac{\varphi^{H}\left(\lambda, \tau^{\prime}\right)}{\varphi^{d}\left(\lambda, \tau^{\prime}\right)}$, and the trade-induced competition effect, $\frac{\varphi^{d}\left(\lambda, \tau^{\prime}\right)}{\varphi^{d}(\lambda, \tau)}$.

The trade-induced competition effect, $\frac{\varphi^{d}\left(\lambda, \tau^{\prime}\right)}{\varphi^{d}(\lambda, \tau)}$ : Since $\tau>\tau^{\prime}$, we have $\frac{P(\tau)}{P\left(\tau^{\prime}\right)}>1$, i.e., a lower trade cost raises market competition and increases the domestic productivity cutoff. Thus, $\frac{\varphi^{d}\left(\lambda, \tau^{\prime}\right)}{\varphi^{d}(\lambda, \tau)}>1$. (result i)

The trade-induced innovation effect, $\frac{\varphi^{H}\left(\lambda, \tau^{\prime}\right)}{\varphi^{d}\left(\lambda, \tau^{\prime}\right)}$ : According to Proposition $2, \varphi^{H}\left(\lambda, \tau^{\prime}\right)<$ $\varphi^{d}\left(\lambda, \tau^{\prime}\right)$ for $\lambda>\lambda_{H}^{\prime}$. Thus, $\frac{\varphi^{H}\left(\lambda, \tau^{\prime}\right)}{\varphi^{d}\left(\lambda, \tau^{\prime}\right)}<1$ for $\lambda>\lambda_{H}^{\prime}$. (result ii)

From (i) and (ii), the sign of $\frac{\varphi^{H}\left(\lambda, \tau^{\prime}\right)}{\varphi^{d}(\lambda, \tau)}-1$ can be ambiguous. If the trade-induced innovation effect dominates the competition effect, i.e., $\frac{\varphi^{H}\left(\lambda, \tau^{\prime}\right)}{\varphi^{d}\left(\lambda, \tau^{\prime}\right)}<<1$, then $\frac{\varphi^{H}\left(\lambda, \tau^{\prime}\right)}{\varphi^{d}(\lambda, \tau)}<1$. This means that the productivity cutoff to export a high quality product after the trade cost reduction is lower than the domestic productivity cutoff before the trade cost reduction. Therefore, firms can produce and export a higher quality product than before, i.e., there will be quality upgrading. If the trade-induced competition effect dominates the innovation effect, i.e., $\frac{\varphi^{H}\left(\lambda, \tau^{\prime}\right)}{\varphi^{d}\left(\lambda, \tau^{\prime}\right)}$ is closer to 1 , then $\frac{\varphi^{H}\left(\lambda, \tau^{\prime}\right)}{\varphi^{d}(\lambda, \tau)}>1$. This means that the productivity cutoff to export a high quality product after the trade cost reduction is higher than the domestic productivity cutoff before the trade cost reduction. Therefore, firms that can produce this product previously can no longer produce this variety at a lower trade cost. The quality range will shrink towards the lower end of the quality ladder.

Note that

$$
\frac{\varphi^{H}\left(\lambda, \tau^{\prime}\right)}{\varphi^{d}\left(\lambda, \tau^{\prime}\right)}=\left(\frac{1+\lambda^{-r} f_{x}}{1+\lambda_{H}^{\prime-r} f_{x}}\right)^{\frac{1}{\theta-1}}
$$

For $\frac{\varphi^{H}\left(\lambda, \tau^{\prime}\right)}{\varphi^{d}\left(\lambda, \tau^{\prime}\right)}$ to be lower but closer to 1 , it must be the case that $\lambda$ is greater but very close to $\lambda_{H}^{\prime}$. It means that the quality drop due to the dominating competition effect happens to those products with quality just above the quality threshold $\lambda_{H}^{\prime}$. Product with quality $\lambda$ greater but further from $\lambda_{H}^{\prime}$ are less likely to be dropped. For those firms that the dropped quality levels are their previous top quality products, after the fall in the trade cost, they can no longer produce those quality varieties and face a shrinkage in the quality range. 
We will now identify the quality or productivity threshold separating the two groups of firms that respond differently to a decrease in trade cost. This quality threshold satisfies

$$
\frac{\varphi^{H}\left(\lambda, \tau^{\prime}\right)}{\varphi^{d}(\lambda, \tau)}=\left(\frac{1+\lambda^{-r} f_{x}}{1+\tau^{\prime 1-\theta}}\right)^{\frac{1}{\theta-1}} \frac{P(\tau)}{P\left(\tau^{\prime}\right)}=1
$$

or

$$
\frac{1+\lambda^{-r} f_{x}}{1+\tau^{\prime 1-\theta}}=\left[\frac{P\left(\tau^{\prime}\right)}{P(\tau)}\right]^{\theta-1} .
$$

For any given change in the trade cost, this quality threshold is given by

$$
\lambda^{*}\left(\tau, \tau^{\prime}\right)=f_{x}^{\frac{1}{r}}\left[1-\left[\frac{P\left(\tau^{\prime}\right)}{P(\tau)}\right]^{\theta-1}\left(1+\tau^{\prime 1-\theta}\right)\right]^{-\frac{1}{r}}
$$

The productivity threshold corresponding to this quality threshold is given by

$$
\varphi^{*}\left(\tau, \tau^{\prime}\right)=\varphi^{d}\left(\lambda^{*}, \tau\right)=\kappa(\tau)^{\frac{1}{1-\theta}} \lambda^{* \frac{r-\gamma}{\theta-1}} .
$$

A firm with productivity $\varphi>\varphi^{*}\left(\tau, \tau^{\prime}\right)$, whether being an incumbent exporter or a new exporter, can upgrade its product quality range after a reduction in trade cost. A firm with productivity $\varphi<\varphi^{*}\left(\tau, \tau^{\prime}\right)$, whether being a new exporter or remaining as a domestic oriented firm, will drop its top quality varieties and contract its product quality range toward the lower-end after a reduction in trade cost.

A change in $\varphi^{*}\left(\tau, \tau^{\prime}\right)$ will determine how firms in a country will respond to a reduction in trade cost, i.e., how large is the share of firms that will upgrade and expand their product quality range and how large is the share of firms that will lower and contract their product quality range.

Proof. (Proposition 6) (a) The first task is to prove that $E_{\tau, L}>E_{\tau, H}$. Using expressions for $\varphi^{L}(\lambda)$ and $\varphi^{H}(\lambda)$ in (25) and (26), the two elasticities of the productivity cutoff with respect to $\tau$ are

$$
\begin{aligned}
E_{\tau, L} & =\frac{d \ln \varphi^{L}(\lambda)}{d \ln \tau} \\
& =\frac{d}{d \ln \tau}\left(\ln \tau-\frac{1}{\theta-1} \ln \kappa+\ln \left[f_{x}^{\frac{1}{\theta-1}} \lambda^{\beta-1}\right]\right) \\
& =1-\frac{1}{\theta-1} \frac{d \ln \kappa}{d \ln \tau}
\end{aligned}
$$


and

$$
\begin{aligned}
E_{\tau, H} & =\frac{d \ln \varphi^{H}(\lambda)}{d \ln \tau} \\
& =\frac{d}{d \ln \tau}\left(-\frac{1}{\theta-1} \ln \kappa-\frac{1}{\theta-1} \ln \left[1+\tau^{1-\theta}\right]+\ln \left[\left(\lambda^{r}+f_{x}\right)^{\frac{1}{\theta-1}} \lambda^{\beta-1}\right]\right) \\
& =-\frac{1}{\theta-1} \frac{d \ln \kappa}{d \ln \tau}-\frac{1}{\theta-1} \frac{d \ln \left[1+\tau^{1-\theta}\right]}{d \ln \tau} \\
& =-\frac{1}{\theta-1} \frac{d \ln \kappa}{d \ln \tau}-\frac{1}{\theta-1} \tau^{1-\theta} \frac{1-\theta}{\tau^{1-\theta}+1} \\
& =-\frac{1}{\theta-1} \frac{d \ln \kappa}{d \ln \tau}+\frac{\tau^{1-\theta}}{\tau^{1-\theta}+1} .
\end{aligned}
$$

Therefore, the difference between the elasticities is

$$
\begin{aligned}
E_{\tau, L}-E_{\tau, H} & =1-\frac{1}{\theta-1} \frac{d \ln \kappa}{d \ln \tau}+\frac{1}{\theta-1} \frac{d \ln \kappa}{d \ln \tau}-\frac{\tau^{1-\theta}}{\tau^{1-\theta}+1} \\
& =1-\frac{\tau^{1-\theta}}{\tau^{1-\theta}+1}=\frac{1}{\tau^{1-\theta}+1} \\
& >0
\end{aligned}
$$

since $\frac{1}{\tau^{1-\theta}+1}<1$.

(b) It is straightforward to show that the difference in elasticities, as shown above, is increasing in $\tau$ since $\theta>1$. 


\section{References}

Amiti, Mary, \& Khandelwal, Amit K. 2013. Import Competition and Quality Upgrading. The Review of Economics and Statistics, 95(2), 476-490.

Antoniades, Alexis. 2015. Heterogeneous Firms, Quality, and Trade. Journal of International Economics, 95(2), 263 - 273.

Baldwin, John, \& Gu, Wulong. 2009. The Impact of Trade on Plant Scale, Production-Run Length and Diversification. University of Chicago Press. https://www.press.uchicago.edu/ucp/books/book/chicago/P/bo6038560.html. Chap. 15, pages 557-592.

Baldwin, Richard, \& Harrigan, James. 2011. Zeros, Quality, and Space: Trade Theory and Trade Evidence. American Economic Journal: Microeconomics, 3(2), 60-88.

Bernard, Andrew B, Redding, Stephen J, \& Schott, Peter K. 2011. Multi-product firms and trade liberalization. Quarterly Journal of Economics, 126(3), 1271-1318.

Berthou, A., \& Fontagne, L. 2013. How do Multiproduct Exporters React to a Change in Trade Costs? Scandinavian Journal of Economics, 115(2), 326-353.

Bhattarai, Saroj, \& Schoenle, Raphael. 2014. Multiproduct firms and price-setting: Theory and evidence from U.S. producer prices. Journal of Monetary Economics, 66, $178-192$.

Bloom, N., Draca, M., \& Van Reenen, J. 2016. Trade induced technical change? The impact of Chinese imports on innovation, IT and productivity. Review of Economic Studies, 83(1), 87-117.

Bustos, Paula. 2011. Trade Liberalization, Exports, and Technology Upgrading: Evidence on the Impact of MERCOSUR on Argentinian Firms. American Economic Review, 304-340.

Crozet, M., Head, K., \& Mayer, T. 2012. Quality sorting and trade: Firm-level evidence for French wine. Review of Economic Studies, 79(2), 609-644.

Eckel, C., \& Neary, J.P. 2010. Multi-product firms and flexible manufacturing in the global economy. Review of Economic Studies, 77(1), 188-217.

Eckel, Carsten, Iacovone, Leonardo, Javorcik, Beata, \& Neary, J. Peter. 2015. Multiproduct firms at home and away: Cost- versus quality-based competence. Journal of International Economics, 95(2), 216-232. 
Fajgelbaum, P., Grossman, G.M., \& Helpman, E. 2011. Income distribution, product quality, and international trade. Journal of Political Economy, 119(4), 721-765.

Fontagne, L., Secchi, A., \& Tomasi, C. 2018. Exporters' product vectors across markets. European Economic Review, 110, 150-180.

Gervais, A. 2015. Product quality, firm heterogeneity and trade liberalization. Journal of International Trade and Economic Development, 24(4), 523-541.

Hallak, J.C., \& Sivadasan, J. 2013. Product and process productivity: Implications for quality choice and conditional exporter premia. Journal of International Economics, 91(1), 53-67.

Iacovone, L. 2012. The better you are the stronger it makes you: Evidence on the asymmetric impact of liberalization. Journal of Development Economics, 99(2), 474485 .

Iacovone, L., Rauch, F., \& Winters, L.A. 2013. Trade as an engine of creative destruction: Mexican experience with Chinese competition. Journal of International Economics, 89(2), 379-392.

Iacovone, Leonardo, \& Javorcik, Beata S. 2008. Multi-product exporters: Diversification and micro-level dynamics. World Bank Policy Research Working Paper Series.

Iacovone, Leonardo, \& Javorcik, Beata S. 2010. Multi-Product Exporters: Product Churning, Uncertainty and Export Discoveries. The Economic Journal, 120(544), 481-499.

Johnson, Robert C. 2012. Trade and prices with heterogeneous firms. Journal of International Economics, 86(1), 43 - 56.

Khandelwal, A. 2010. The long and short (of) quality ladders. Review of Economic Studies, 77(4), 1450-1476.

Kugler, M., \& Verhoogen, E. 2012. Prices, Plant Size, and Product Quality. Review of Economic Studies, $\mathbf{7 9}(1)$, 307-339.

Manova, K., \& Zhang, Z. 2012. Export prices across firms and destinations. Quarterly Journal of Economics, 127(1), 379-436.

Manova, Kalina, \& Yu, Zhihong. 2017. Multi-product firms and product quality. Journal of International Economics, 109, 116-137. 
Mayer, T., Melitz, M.J., \& Ottaviano, G.I.P. 2014. Market size, competition, and the product mix of exporters. American Economic Review, 104(2), 495-536.

Melitz, M.J. 2003. The impact of trade on intra-industry reallocations and aggregate industry productivity. Econometrica, 71(6), 1695-1725.

Verhoogen, E.A. 2008. Trade, Quality Upgrading and Wage Inequality in the Mexican Manufacturing Sector. Quarterly Journal of Economics, 123(2), 489-530. 